Portland State University

PDXScholar

1996

Urgent Care Center Location: an Empirical Analysis of their Locations in Relation to Demographic, Socioeconomic, and Land Use Factors: a Case Study of Portland, Oregon

Abdullah Alfaiz

Portland State University

Follow this and additional works at: https://pdxscholar.library.pdx.edu/open_access_etds Let us know how access to this document benefits you.

Recommended Citation

Alfaiz, Abdullah, "Urgent Care Center Location: an Empirical Analysis of their Locations in Relation to Demographic, Socioeconomic, and Land Use Factors: a Case Study of Portland, Oregon" (1996).

Dissertations and Theses. Paper 1328.

https://doi.org/10.15760/etd.1327

This Dissertation is brought to you for free and open access. It has been accepted for inclusion in Dissertations and Theses by an authorized administrator of PDXScholar. Please contact us if we can make this document more accessible: pdxscholar@pdx.edu. 


\title{
URGENT CARE CENTER LOCATION:
}

\section{AN EMPIRICAL ANALYSIS OF THEIR LOCATIONS IN RELATION TO DEMOGRAPHIC, SOCIOECONOMIC, AND LAND USE FACTORS. \\ A CASE STUDY OF PORTLAND, OREGON}

\author{
by \\ ABDULLAH ALFAIZ \\ A dissertation submitted in partial fulfillment of the \\ requirements for the degree of \\ DOCTOR OF PHILOSOPHY \\ in \\ URBAN STUDIES
}

Portland State University

1996 


\section{DEDICATION}

In the memory of my father and to my mother, for their love and faith in me.

To my Wife, Rabah, and my Daughters, Nora, and Sara for their patience, love, support, and devotion. 


\section{DISSERTATION APPROVAL}

The abstract and dissertation of Abdullah Alfaiz for the Doctor of Philosophy in Urban

Studies was presented on December 8, 1995 and accepted by the dissertation

committee and the doctoral program.

COMMITTEE APPROVALS:

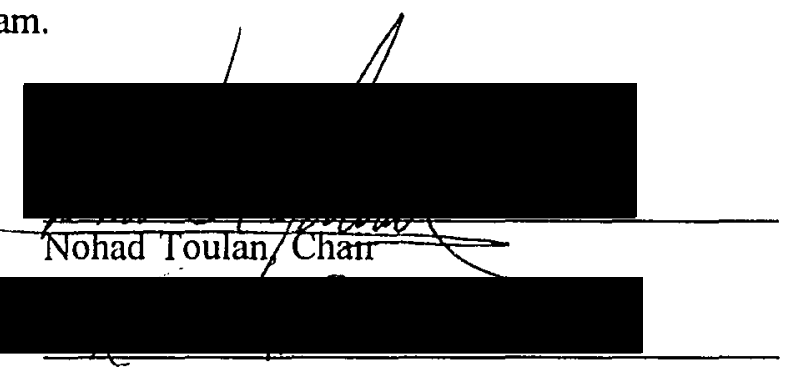

Kenneth Dueker

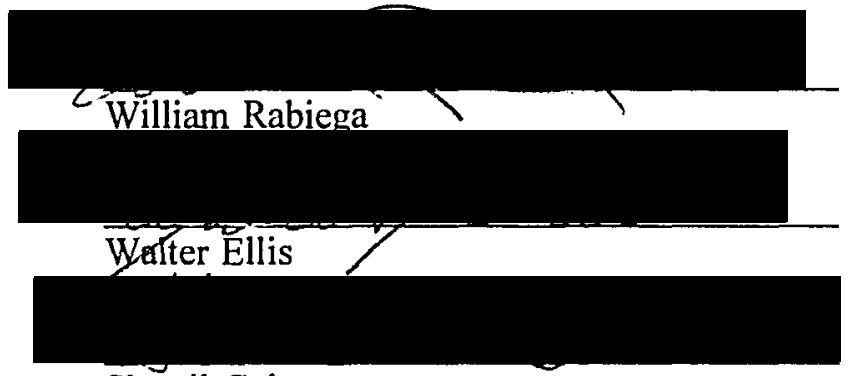

Sherril Gelmon

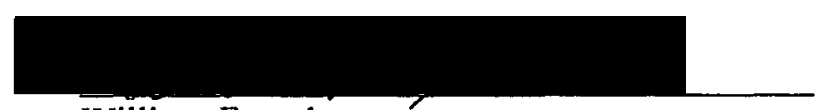

William Feyerherm

Representative of the Office of Graduate Studies

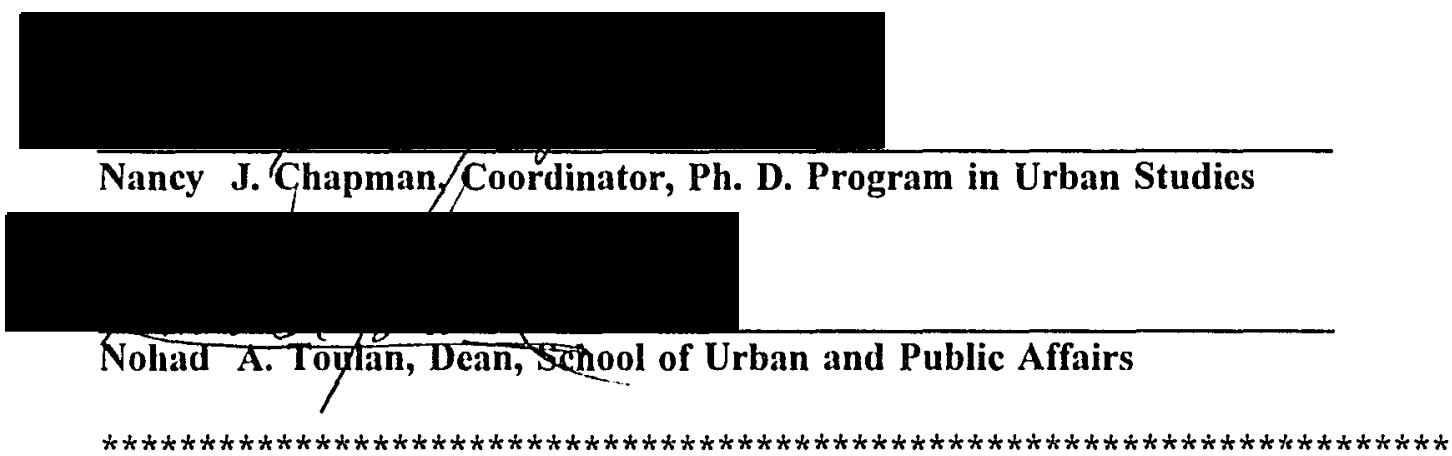

ACCEPTED FOR PORTLAND STATE UNIVERSITY LIBRARY

by

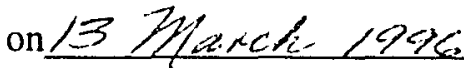




\begin{abstract}
An abstract of the dissertation of Abdullah Alfaiz for the Doctor of Philosophy in Urban Studies presented December 8, 1995.
\end{abstract}

Title: Urgent Care Center Location: An Empirical Analysis of Their Locations in Relation to Demographic, Socioeconomic, and Land Use Factors. A Case Study of Portland, Oregon.

Urgent Care Centers (UCCs) are a recent innovation in the American system of health care delivery. The number of UCCs has increased significantly in recent years. Many researchers point out that the rapid growth of UCCs is expected to escalate during the next few decades. This growth will create more competition among providers of these facilities in the health care market, and the competition could lead to an uneven distribution of UCCs within cities.

While health officials and planners are interested in attracting more patients by expanding UCC services, they are often unfamiliar with the factors that go into site selection decisions. Understanding the factors influencing UCC location is crucial to explaining why UCCs cluster in certain urban areas, while other areas are under-served. It is also important for providers who want to enhance accessibility of special population segments to UCC locations.

This study uses the Portland metropolitan area as a case study. Due to the 
lack of access to providers' propriety data, the specific problem targeted here uses publicly available data as a proxy for providers' data to determine the factors influencing UCC location. The essence of this research is to show how these factors explain and predict existing locations of UCCs and to find out how well this publicly available data explains UCC providers' locational behavior. Most of the data for this study is provided by Metro of Portland. Other data are collected utilizing surveys and data from different public agencies and published reports. Logit analysis is used to find out which factors explain existing UCC location. The empirical findings of this research substantiate the existence of a strong relationship between the location of UCCs and land use factors. This study highlights the complexity and importance of understanding the factors influencing the location of UCCs. It rejects prior arguments that UCC location is influenced by some demographic and socioeconomic factors, while it introduces land use factors as the major determinants of UCC location. However, the this study concluded that land use factors influence considered a rare phenomena that should be carried out for future research and that demographic factors may still have an indirect effect on UCC location. 


\section{ACKNOWLEDGEMENTS}

I would like to acknowledge all the help and support given to me by all my committee members. I would like most to thank Dr. Nohad Toulan for his patience and guidance and support throughout this dissertation. Further, I would like to thank Dr. Sherril Gelmon for her friendly comments and advice. I am grateful to both Dr. Kenneth Dueker and Dr. William Rabiega for their methodological suggestions and comments. My special thanks to Dr. Walter Ellis for his support and help to attain some of the data needed for this study. This work would not have been accomplished without the help of Nina Cramer and Robert Knight of Metro, and several other individuals. 


\section{TABLE OF CONTENTS}

\section{PAGE}

ACKNOWLEDGMENTS $\ldots \ldots \ldots \ldots \ldots \ldots \ldots$ ii

LIST OF TABLES $\ldots \ldots \ldots \ldots \ldots \ldots \ldots \ldots$ viii

LIST OF FIGURES $\ldots \ldots \ldots \ldots \ldots \ldots \ldots \ldots \ldots$ ix

\section{CHAPTER}

I. Introduction $\ldots \ldots \ldots \ldots \ldots \ldots \ldots \ldots \ldots$

Study Objectives $\ldots \ldots \ldots \ldots \ldots \ldots \ldots \ldots$

Organization of the Study $\ldots \ldots \ldots \ldots \ldots \ldots$

II. Literature Review ............... 7

An Historical Perspective of

Urgent Care Centers $\ldots \ldots \ldots \ldots \ldots \ldots \ldots$

Definition ................ 7

The Evolution of UCCs in the U.S. . . . . . . 10

Forces Underlying Change to UCCs . . . . . 10 
Urgent Care Centers in Portland, Oregon . . . . . 12

Theoretical Perspectives on Factors Influencing Urgent Care Center Location . . . . . . . . . 14

Estimating Health Service Area $\ldots \ldots \ldots$. . . 17

Factors Influencing UCC Location . . . . . . 20

Demographic and Socioeconomic Factors . . . . 22

Demographic Characteristics $\ldots \ldots \ldots \ldots \ldots 23$

Age $\ldots \ldots \ldots \ldots \ldots \ldots \ldots 24$

Gender .................26

Marital Status and Children $\ldots \ldots \ldots \ldots 27$

Race $\ldots \ldots \ldots \ldots \ldots \ldots \ldots \ldots$

Socioeconomic Factors . . . . . . . . . 29

Income $\ldots \ldots \ldots \ldots \ldots \ldots \ldots \ldots$

Education and Employment $\ldots \ldots \ldots \ldots 30$

Health Insurance $\ldots \ldots \ldots \ldots \ldots \ldots$

Competition ............... 33

Land Use Factors $\ldots \ldots \ldots \ldots \ldots \ldots \ldots$

Economies of Scale . . . . . . . . . . 35

Accessibility and Consumer Behavior ... . 36

Accessibility and Convenience

of Urgent Care Centers $\ldots \ldots \ldots \ldots \ldots$

Summary .................. 40 
III. METHODOLOGY $\ldots \ldots \ldots \ldots \ldots \ldots \ldots \ldots \ldots$

Approaches to Examining Locational Factors . . . . . 44

Research Design . . . . . . . . . . . . . 49

Statement of the Problem . . . . . . . . . 49

Research Question .............51

Research Hypotheses . . . . . . . . . . 51

Study Scope and Sample .......... 53

The Study Area $\ldots \ldots \ldots \ldots \ldots \ldots$

Research Model .............. 54

Accessibility to Urgent Care Centers in Portland,

Oregon $\ldots \ldots \ldots \ldots \ldots \ldots \ldots \ldots$

Data Sources and Variable Measurements ... 60

IV. URGENT CARE CENTERS IN PORTLAND, OREGON $\ldots \ldots \ldots \ldots \ldots \ldots \ldots \ldots \ldots \ldots \ldots \ldots$

The Definition of Urgent Care Center . . . . . . 63

Urgent Care Centers in Portland, Oregon . . . . . 65

The Survey $\ldots \ldots \ldots \ldots \ldots \ldots \ldots 6$

The Questionnaire $\ldots \ldots \ldots \ldots \ldots \ldots 6$

The Survey Results $\ldots \ldots \ldots \ldots \ldots \ldots \ldots$

V. ANALYSIS $\ldots \ldots \ldots \ldots \ldots \ldots \ldots \ldots \ldots$ 
The Design of Empirical Analysis $\ldots \ldots \ldots \ldots \ldots 73$

Results $\ldots \ldots \ldots \ldots \ldots \ldots \ldots \ldots \ldots 77$

Results of the Logit Model . . . . . . . . . 77

Conclusions $\ldots \ldots \ldots \ldots \ldots \ldots \ldots \ldots \ldots \ldots$

VI. RESEARCH FINDINGS $\ldots \ldots \ldots \ldots \ldots \ldots \ldots \ldots$

Land Use Factors' Influence On

Urgent Care Center Location $\ldots \ldots \ldots \ldots \ldots$. . . 84

Land Use Factors $\ldots \ldots \ldots \ldots \ldots \ldots$

Demographic and Socioeconomic Factors . . . . . 87

Other Factors Influencing Urgent Care

Center's Location $\ldots \ldots \ldots \ldots \ldots \ldots \ldots$

Conclusions $\ldots \ldots \ldots \ldots \ldots \ldots \ldots \ldots$

VII. DISCUSSION AND RESEARCH IMPLICATIONS . . . 91

Research Limitations $\ldots \ldots \ldots \ldots \ldots \ldots$

Planning and Policy Implications $\ldots \ldots \ldots \ldots 93$

Suggestions for Further Research $\ldots \ldots \ldots \ldots . \ldots 94$

REFERENCES .....................99 


\section{APPENDICES}

A. Survey Questionnaire and Results . . . . . . . . 109

B. Descriptive Statistics $\ldots \ldots \ldots \ldots \ldots \ldots \ldots \ldots$

C. Logit Analysis Results . . . . . . . . . . . 124 


\section{LIST OF TABLES}

TABLE

PAGE

I Alternative Accessibility Measures $\ldots \ldots \ldots \ldots \ldots$

II List of Urgent Care Providers

in Portland, Oregon, $1990 \ldots \ldots \ldots$. . . . . . . 69

III Comparison of Means for the Demographic

and Socioeconomic Variables ............ 75

IV The Results of the Logit Model $\ldots \ldots \ldots \ldots \ldots \ldots$

V The Results of the Logit Model

Using the Population Size $\ldots \ldots \ldots \ldots \ldots$. . . 80 


\section{LIST OF FIGURES}

FIGURE

1. Map of the Location of All Providers of

Urgent Care Centers in Portland, Oregon, $1990 \ldots . . .14$

2. Annual Rate of Visits to Office-Based Physicians

by Patients' Age and Gender: United States, 1991 . . . 24

3. Annual Rate of Visits to Office-Based

Physician by Patients' Age and Race . . . . . . . 29

4. Outpatient Payments by Source Type ... . . . . 32

5. Map of the Study Area of the Tri-counties

of Portland, Oregon, $1990 \ldots \ldots \ldots \ldots$

6. Map of Urgent Care Centers in

Portland, Oregon, $1990 \ldots \ldots \ldots \ldots \ldots \ldots$ 


\section{CHAPTER I}

\section{INTRODUCTION}

Urgent Care Centers (UCCs), sometimes referred to as freestanding ambulatory surgery centers (FASCs), are a recent innovation in the American system of health care delivery. UCCs remain open 24 hours a day and offer urgent care with no appointment required (Daft and Bush, 1990; Lumpkin and Tudor, 1990). UCCs are challenging traditional medical care with an adaptation of modern business practices to the health care delivery system (Plested, 1991; Lowell-Smith, 1993). "Health service rendered to patients not confined to a bed is the most common mode of delivery of health services in the United States today" (Burns, 1991).

The number of UCCs has increased significantly in recent years (Ortinau, 1986; Cashman et al., 1991a; Malone, 1995). Most researchers point out that the rapid growth of UCCs is expected to escalate during the next few decades (Burns, 1991; Cashman et al., 1991a). This growth will create more competition among providers of these facilities in the health care market, and the competition could lead to an uneven distribution of UCCs within cities (Schul et al., 1994).

This study uses the Portland metropolitan area as a case study to provide an explanatory insight into the factors which affect existing locations of UCCs in urban 
areas. Due to the lack of access to providers' propriety data, the specific problem targeted here uses publicly available data as a proxy for providers' data to evaluate and determine the factors influencing UCC location. The essence of this research is to find out how well this publicly available data explains UCC providers' locational behavior. Most of the data for this study was provided by Metro, the regional governing and planning agency in Portland, Oregon. Other data were collected utilizing telephone surveys and data from various public and private agencies and published reports.

Understanding the factors influencing UCC location is crucial in explaining why UCCs cluster in certain urban areas, while other areas are underserved. This understanding is important for planners and providers who want to enhance accessibility of special population segments to UCC location. Prior research identifies demographic, socioeconomic, and land use factors as the major influences on UCC location. This research examines the relationship between existing UCCs' locations and the above factors. Logit analysis was used to find out which factors explain existing UCC location, and whether existing patterns of UCC location are representative of what prior research suggests.

The innovation of UCCs in the health care delivery system is a result of many forces that are shaping the industry as a whole. These forces include the implementation of the Medicare Prospective Payment System (PPS) (Helbing et al., 1990; Clark and Krentz, 1991); the advent of technological advances (MacDowell and Perry, 1990); the response to the rising costs of health care services, and the 
increasing number of physicians in the industry (Kotler and Clarke, 1987; Dant and Bush, 1990; Lumpkin and Tudor, 1990).

These forces have prompted existing providers of health care facilities (HCFs) to expand services and to consider several market-oriented stances that recognize existing market segments, such as managed care plans, HMOs, and PPOs, and that target consumer groups such as the elderly, women, and families with children (Shortell et al., 1990; Burns, 1991; Gruca and Nath, 1994; Schul et al., 1994).

While health officials and planners are interested in and eager to attract more patients by expanding UCC services, they are often unfamiliar with the inter- and extraorganizational factors that go into site selection decisions. Interorganizational factors pertain to the internal decision-making process within the organization (Ross et al., 1984; Kovner, 1990). Extraorganizational factors are external to the organization and are specific to the urban setting of facilities, which include demographic, socioeconomic and land use factors. This study confines itself to studying extraorganization factors affecting UCCs' locations (Ross et al., 1984; Winston, 1985; Kovner, 1990). In contrast with the considerable amount of research available on traditional $\mathrm{HCFs}$, little has been published about the characteristics of existing UCC locations. According to Lowell-Smith (1993), "Most studies of FASC have concentrated on utilization and competition factors rather than their location and geographic distribution." Recently, there has been greater interest in understanding the selection and distribution of UCCs in cities (Kovner, 1990; Kassaye and Tseng, 1990; Lancaster and Boissoneau, 1990; Nauert, 
1992; Heischmidt et al., 1993). But, while several studies have examined the spatial distribution pattern of traditional HCF locations, (Bridgman, 1978; McLafferty, 1986; Mayhew, 1986), none has examined the factors affecting the location of UCCs. Available research on UCCs focuses on patients' choices and satisfaction with UCCs (Wotruba et al., 1985; Lancaster and Boissoneau, 1990; Dolinsky and Caputo, 1990). None has contributed to understanding what factors a provider considers when deciding where within an urban area to locate a UCC. As Lowell-Smith concluded in a recent study for the intra-regional location variations of freestanding ambulatory surgery centers (FASCs):

This paper has presented only a macro-scale analysis of the spatial distribution of FASCs. Important micro-scale issues have not been addressed. Questions for future research might include the locational preference of FASCs, competition, accessibility, and market thresholds. (Lowell-Smith, 1993, p. 406)

\section{Study Objectives}

The primary objective of this dissertation is to examine demographic, socioeconomic, and land use factors specific to existing UCC locations in urban areas. Understanding these factors and identifying any patterns common to existing UCC locations is central to determining why providers selected the sites where these UCCs are located. Since there is very little research or available data on the subject, this work is the basic grounding for future health services planning research on UCCs, and can be extended to other HCF spatial interaction analysis and spatial decision support systems. Moreover this research will improve understanding of the 
phenomenon of UCC growth in cities and contribute to current efforts to improve accessibility of health care to underserved populations.

Consequently, this study will trace the evolution of UCCs in the U.S. from their beginning to the present and explore the characteristics of existing UCC service areas in search of a common denominator. Further, the study will provide a survey of existing UCCs in Portland, Oregon, and extract some important unavailable data basic for any future research of UCCs in Portland.

The purpose is to gain a general perspective of UCC locations with respect to these characteristics. Accordingly, the analysis of UCC market areas' characteristics should provide insight into the existing strategy for selecting a UCC site.

This study argues that demographic, socioeconomic, and land use factors are important in understanding the decisions made in selecting the sites of existing UCCs. Given the complexity of the issue, a logit model will be used to examine and identify each demographic, socioeconomic and land use factor's effects and significance upon existing UCCs' locations in cities. The analyses will use parts of the metropolitan area of Portland, Oregon.

This study intends to delineate such areas and to investigate the characteristics of the urban areas where providers have located their UCCs to see if these areas have anything in common.

\section{Organization of the Study}

The study is divided into seven chapters. Chapter I, the introduction, defines 
the general scope of the problem, the study objective, and its organization. Chapter II presents the literature review, which gives a brief definition of UCCs, their evolution in the U.S. and in Portland, Oregon, and the forces underlying the change to UCCs. It also provides a review of location theories with respect to UCC location and a discussion of the major factors affecting UCC location. Chapter III discusses the methodology of this research in terms of approaches to problem examination and research design. Chapter IV provides the operational definition of UCCs for the purpose of this study and describes the telephone survey used to locate UCCs in Portland, Oregon. Chapter V provides a discussion of the empirical analysis of UCC location in relation to demographic, socioeconomic, and land use factors and the conclusions of the analysis and the research results. Chapter VI discusses the major research findings. Finally, Chapter VII briefly addresses the planning and policy implications of this research and provides suggestions for further research. 


\section{CHAPTER II}

\section{LITERATURE REVIEW}

This chapter presents a theoretical perspective on the relationship between Urgent Care Centers (UCCs) and the demographic, socioeconomic, and land use factors in urban areas. The first part provides an historical perspective of UCCs. It defines UCCs and summarizes their background and evolution in the U.S., and the forces underlying changes to UCCs. Included is an introduction to UCCs in Portland. The second part presents an overview of theories and empirical studies for UCC and related health care facility location. Also included is a discussion of health care facility location problems and the different perspectives and approaches to achieve better UCC location. More discussion is provided for medical service areas and the major factors influencing UCC location, which cover all demographic, socioeconomic, and land use factors. This chapter ends with a summary of UCC locational problems and different approaches to measure medical service area and accessibility and the major factors influencing UCC location.

\section{AN HISTORICAL PERSPECTIVE OF URGENT CARE CENTERS}

\section{$\underline{\text { Definition }}$}

A UCC is generally defined as a free-standing ambulatory facility that 
comprises general practitioner offices and an ambulatory unit (Kovner, 1990). UCCs are distinctive for their "no-appointment-necessary" concept, their extended hours of operation (seven days per week and on holidays), and the availability of basic X-ray service. Their intent is to convey an image of convenience while providing quality care that fits with modern !ife (Phillips and Reeder, 1987; Lumpkin and Tudor, 1990; Cashman et al., 1991b; Kovner, 1990). UCCs are distinguished by their varying or limited provision of urgent care, which contrasts with ambulatory centers routinely offering emergency care.

However, since UCCs are a recent evolution, health care literature uses several names for them which include: Free-standing Ambulatory Walk-in Clinics (FAWICs), Freestanding Ambulatory Surgery Centers (FASCs) (Lowell-Smith, 1993), Hospital Satellite Outpatient Clinics (HSOCs), and Emergency Medical Walk-in Clinics (EMWCs) (Winston, 1985; Ortinau, 1986; Wolfson et al., 1993). These facilities are essentially the same, but they may vary in the size of their ambulatory function compared to their clinical function (Ross et al., 1984). UCCs may also vary according to their ownership. Some UCCs are owned by major hospitals and some by smaller private providers. UCCs are difficult to define largely because of the diversity of practitioners and services that are included under that name. There is no single uniform definition for urgent care (Kovner, 1990; Plane and Rogerson, 1991; Morrill, 1993). It is beyond the scope of this study to cover all types of UCCs; therefore, the focus here is on UCCs that offer extended hours of general urgent care treatment without prior appointment. According to the 
definition of UCCs offered above, both hospital-based emergency centers and freestanding ambulatory-urgent care centers can be considered UCCs.

According to Williams and Guerra (1985), ambulatory outpatient care facilities are the "primary source of contact" with people seeking health care. They are the "backbone of the health care system." This may indeed explain the great pressure on providers to capitalize on the market by shifting to UCCs. According to Burns (1991, p. 54):

The percentage of physician fees originating from outpatient encounters with patients has risen dramatically. This change has altered the economic basis of physician practices and made their success more dependent on ambulatory delivery and financing arrangements ... Supporters of the walk-in clinic mechanism have viewed the concept as an important market-driven alternative for consumers who have been dissatisfied to some extent with the standard dimensions.

In essence, the aim of the shift to UCCs is to attract newcomers and relocated, uninsured, dissatisfied, and even employer-covered users. This was supported by the conclusions of Bowers et al. (1994, p. 42) that:

In fact, physician referrals currently account for more than half of providers' patients. As a result, physicians and UCCs can affect the survival of the health care organization, making them a crucial focus for health care providers.

It is difficult to obtain a broader understanding of the role of UCCs without having in mind some idea of how they developed. 
The Evolution of Urgent Care Centers in the U.S.

The growth of UCCs in the U.S. began in the 1970s but continued to escalate in the late 1980s. The first UCC was established in 1970 in Phoenix, Arizona (Wolfson and Levin, 1985, Lowell-Smith 1993). In 1975 there were five UCCs operating in the U.S. By 1980 the number grew to more than 100 UCCs ( Winston, 1985). Cashman et al. (1991a) and Malone (1995) noted this rapid growth. Between 1978 and 1984, the average annual growth rate was about 71 percent. From 1980 to 1989 the number of UCCs in the U.S. grew from 127 to 1221 (Wolfson et al., 1993). The growth of these facilities is believed to be negatively affecting the traditional, general hospital's bed-use rate (Cashman et al., 1991a).

Meanwhile, the trend on the in-patient side has moved in the opposite direction (Wolfson et al., 1993; Dennison et al., 1993; Malone, 1995). By 1991, over half of all hospital-based surgeries were being performed in an out-patient setting (Fraser et al., 1993). An example of such a trend is apparent in Medicare program data presented by Helbing et al. (1990), which shows a shift from hospital in-patient to out-patient care. From 1984 through 1987, program payment for Medicare outpatient services increased from $\$ 3.4$ billion to $\$ 5.6$ billion, an average annual rate of growth of 18.2 percent (Helbing et al., 1990).

\section{Forces Underlying Change to Urgent Care Centers:}

The shift to UCCs is mostly attributed to the implementation of the Medicare 
Prospective Payment System (PPS) in 1983 (Hebing et al., 1990; Fraser et al., 1993; Wolfson et al., 1993). This change is part of a host of economic, political, and demographic forces, all of which reflect the larger social and political transformation of the American health care system (McLafferty 1982). These changes have continued since the 1980 s and were expected to promote the change to UCCs. Nevertheless, PPS encouraged hospitals to place patient treatment in outpatient sites when they were more appropriate and less costly than in-patient care (Petrie, 1992; Helbing et al., 1990).

Several authors suggest that the implementation of the Medicare PPS for inpatient care has created the need for shorter stays in hospitals, which, in turn, has resulted in large increases in the use of UCCs (Helbing et al., 1990; Clark and Krentz, 1991; Wolfson, 1993). Other authors suggest that a major reason for the shift to UCCs is the advent of technological advances using new laser applications, and computerized surgical instruments and diagnostics. These advances have reduced the need for lengthy in-patient stays and recovery times and encouraged the move to outpatient UCCs (MacDowell and Perry, 1990; Lowell-Smith, 1993). Miller and Sulvetta (1992, p. 135) suggest that technological advances are the most important force behind the shift to treatment in out-patient settings, while PPS has only "added momentum to this process." Another cited reason for UCCs' evolution is the response to the rising costs of health care services and the increasing number of physicians in the industry (Dant et al., 1990; Lumpkin and Tudor, 1990). Additionally, concerns about cost containment have also motivated the shift to 
treatment in out-patient settings (Helbing et al., 1990; MacDowell and Perry, 1990).

Changing insurance payment standards forced many insurance companies to specify that certain procedures would be covered only if performed on an out-patient basis (MacDowell and Perry, 1990). Some health planners even suggest that the main reason for the development of UCCs is to create a referral marketing technique (Kovner, 1990; Salmon, 1991; Burns, 1991; Bowers, 1994).

The effect of changes on the consumer side were overlooked in the literature. It must be mentioned here that changes in consumer income, life styles, suburbanization and the increasing entry of women in the work force, may have contributed to the need for a more convenient way to get urgent care, a need which is met by UCCs. As Lowell-Smith ( 1993, p. 399) pointed out:

This desire for convenient (both spatial and temporal), quality, and cost-effective health care when the patient wants it rather than when the physician is available has aided the growth of both outpatient surgery centers and other forms of nontraditional health care.

\section{Urgent Care Centers in Portland, Oregon}

According to Oregon Hospital Statistics (OHS 1991), expansion of off-site outpatient services is at the top of the list of current trends in the hospital industry in Oregon. OHS (1991) confirms that between 1987 and 1991, hospital revenues attributed to out-patient care increased from 24 percent to 32 percent and the number of out-patient visits increased by 61 percent, from 2.3 million to 3.7 million visits. 
OHS (1991) also emphasizes the effect of the 1983 PPS in reducing patient stays at Oregon hospitals and encouraging more out-patient treatment. Portland is an area where there are higher proportions of managed care (HMOs) than in other cities in the U.S. which are competing with each other. Moreover, most major urgent care providers are establishing new insurance schemes for major employers. Experts predict a growing trend of hospitals directly contracting with employers for health care coverage, rather than providing coverage through an insurance carrier (Rocco, 1993).

There are several providers of traditional medical clinics in the Portland metropolitan area; however, the major providers of UCCs are discussed in Chapter IV. They include the Sisters of Providence (Oregon), Legacy, Kaiser Permanente, and Oregon Health Sciences University (OHSU). According to OHS, 1991, "Competition is rife" between Legacy and Sisters of Providence. These two providers operate 16 of 52 UCCs in Portland (see Figure 1). The Sisters of Providence is a non-profit organization which consists of three companion groups of hospitals: St. Vincent's Hospital, Providence of Portland, and Providence of Milwaukee. Legacy, on the other hand, is a not-for-profit health system which includes Emanuel Hospital, Good Samaritan Hospital, Meridian Park Hospital, Mount Hood Medical Center, and several Immediate Care Centers throughout the metropolitan area. A complete survey of existing UCCs in Portland is presented in greater depth in Chapter IV. 
FIGURE 1

MAP OF THE LOCATION OF ALL PROVIDERS OF URGENT CARE IN PORTLAND, OREGON, 1990

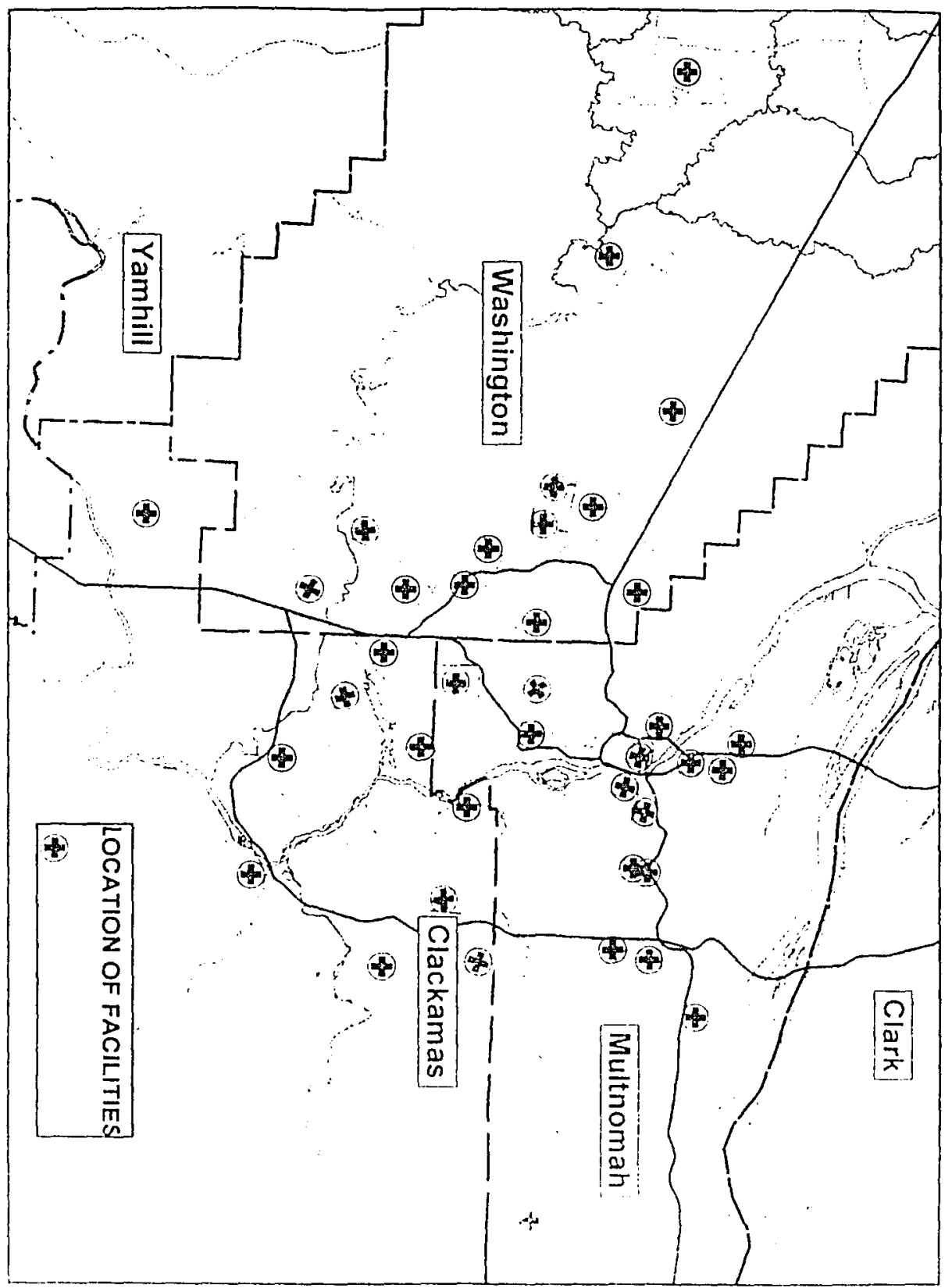

Source: Produced by an application of address matching using GIS. 


\section{Theoretical Perspectives On Factors Influencing Urgent Care Center Location}

A substantial amount of research has been published on the relationship between household characteristics and product consumption; however, in health care, understanding such relations is somewhat difficult (Ghosh and McLafferty, 1987). Researchers agree that there is a relation between demographic characteristics and health care product consumption, but little has been published on the subject.

Urban sprawl and shifts of areas of population growth, witnessed today in many cities of the world, have made siting HCFs a difficult task. According to Reinke (1988), "Health system research is complicated in another way; because it is carried out in the community, it includes multiple variables not easily controlled."

Nevertheless, the location of a health care facility is of paramount importance in determining the efficiency of delivery. The accessibility of such a unit to the surrounding community and the equity in the distribution of HCFs with regard to the whole population can be considered a proxy factor for measuring HCF effectiveness.

Some researchers have already taken major steps in suggesting ways to achieve greater efficiency in the distribution of urban facilities and HCFs. Prior research has involved great effort in calculating and projecting future needs based on population forecasts and many advanced, complex statistical models and algorithms (Rushton and Goodchild, 1973; Meade, 1974; Wagner and Falkson, 
1975; Spiegel and Hyman 1978; Rushton, 1979; Oppenhein, 1980; Goodchild and Noronha, 1983; Ghosh and Rushton, 1987; Samet, 1990; Estes, 1991; Keren and Lewis, 1993). However, most of these efforts have failed to bring about a precise methodology or definition of the most efficient structure for delivering health facilities. Planners and health officials have long tried to increase the effectiveness and accessibility of the health care system, but were always daunted by its complexity (Mayhew, 1986; Reinke, 1988; Gruca and Nath, 1994; D'Amico et al., 1994). This study argues that one basic reason for the fruitlessness of these efforts is their failure to determine and understand the relative influence or weight of the major factors affecting HCF location. Therefore, a better understanding of the influence of each factor in location analysis is very useful in assigning weights to each factor to gain more precise results in most location allocation and spatial interaction models.

Hence, the aim of the next section is to explore, from different perspectives, the problems of UCC location by describing the different planning efforts and methods used for achieving better HCF location and delineating the HCF service area. This will smooth the way to understanding the factors affecting UCC location with respect to population distribution. The intent here is first to examine these efforts to find their current disposition and why they do not provide an efficient explanation for HCF location, and, second, to identify the characteristics of UCC users. 
Estimating Health Service Area (HSA)

Most health care planners agree that a market assessment for any HCF system must typically include:

1. delineation of service area,

2. a demographic and socioeconomic profile,

3. a competitor profile, and

4. regulatory reviews (Massey and Blake, 1987; Clark and Krentz, 1991;

Nauert, 1992, Zwanziger et al., 1994).

According to Zwanziger (1994, p. 430): "A substantial body of literature has been devoted to developing and supporting a variety of different approaches to defining hospital market areas." Estimating an HCF service area lies at the core of ensuring an efficient supply of health care to consumers (Basu, 1982). Understanding the characteristics of the targeted areas is an essential step toward effective use of available resources. Massey and Blake (1987, p. 15) point out that "to perform this task efficiently, marketing planners should identify the geographic bounds within which they can reasonably expect to attract clients."

Since 1945, several analyses have been conducted to come up with a measure of HCF service area. Different definitions were used including geographic boundaries (state or county lines), administrative boundaries (school or hospital districts), and empirical boundaries (distance decay or weighted distance boundaries) (Bay and Nestman, 1980; Basu, 1982; Ross et al., 1984; Massey and Blake, 1987). The earliest study in this context was conducted in 1945 by Ciocco and Altenderfer. 
Using birth statistics, they studied patient origin-destination in order to establish "medical trade" areas (Ciocco and Altenderfer, 1945; Bay and Nestman, 1980; Basu, 1982). A number of efforts since then have been conducted by other researchers in attempts to develop methodologies for estimating HCF service areas. However, most of these studies faced unresolved difficulties. According to Bay and Nestman (1980), these difficulties lie in a lack of data, inappropriately sized geographic units, and increasing mobility and urbanization. Because it is very complicated to understand patients' movement to HCFs, most HCFs do not have predetermined jurisdictional boundaries (Zwanziger et al., 1994).

Beckham (1984) suggested the use of spatial analysis to specify $\mathrm{HCF}$ geographic area. His peripheral penetration model (PPM) produces two standard boundaries, core and periphery service areas. The core service area stretches out five miles from the center, while the periphery may stretch out another five to ten miles. This standard may be of some help to health care providers, but it does not make the distinction between the attraction of large hospitals and that of smaller HCFs (Basu, 1982). The size of the facility is very important to understand before any service area boundaries can be devised (Massey and Blake, 1987).

Massey and Blake (1987) provided the most reasonable approach to estimating service area boundaries. Their model includes several factors that determine the size and attractiveness of an out-patient clinic, such as number of physicians or beds. Based on Beckham's (1984) PPM findings, Massey and Black suggested the use of the "boundary model," a common gravity approach using breaking distance 
between two facilities based on their relative attractiveness. The service unit analysis was applied to the pediatric service units of five hospitals in a southeastern U.S. city of moderate size. Their findings indicate that facility service areas for the five units vary, according to $\mathrm{HCF}$ size, ranging from one to 2.15 miles in diameter. However, their conclusion was that HCFs vary in their attractiveness to patients according to the way weights are assigned to each facility. This was supported by a recent study of emergency centers in Quebec, Canada. The study found that average weighted distance for attendance at emergency centers varies with age. For patients over 65 , the distance was 0.9 miles, while for those under 65 , it was 2 miles (Philibert et al., 1992). Finally, a study was conducted on the spatial patterns of attendance at general practitioner services (GPS) in Gisborne, a small city in New Zealand, which found that most trips were within three miles of a GPS. Similar studies in Aberdeen, Scotland, and Liverpool, England, found that trips to a GPS to be about two miles (Hays et al., 1991).

In conclusion, HCF service area boundaries are difficult to estimate. Scholars have suggested several approaches to estimating $\mathrm{HCF}$ service areas but were unable to provide an acceptable measure. Most approaches are classified under political, administrative, or empirical definitions. The empirical definition is the most commonly used, since it is more accurate and particular to the size and influence of the area of attractiveness (Meade, 1974; Mayhew, 1986).

Although the latest four studies estimating HCFs' market boundaries differ in their settings and HCF type, they still can be useful in estimating UCC service 
areas. Since the types of facilities in the latter studies are essentially similar in size and function to UCCs, the average figure can be used regarding UCC service areas. The average distance in the four studies is 2.5 miles and can be suggested as market boundaries for UCCs in this study. Once a delineation of service area is completed, the demographic, socioeconomic, and land use factors should be examined.

\section{Factors Influencing UCCs Location}

HCFs are very different in nature from most urban facilities. This explains, in part, the difficulty researchers faced in identifying the factors affecting their location. For services where individuals pay directly, they may use supply and demand economics to evaluate the cost of service. However, in health care, health insurance and imperfect information among consumers about quality or quantity of care may distort price signals (Mayhew, 1986; Browning, 1993; Hardon, 1991). This difficulty stems from the fact that the health care system, especially in the U.S., is very complicated (Wagner et al., 1994, Zajas, 1994). Several parties are involved in the process of delivering health care. Those parties include providers, insurers, physicians, and patients. Each of these parties contribute to the complexity in understanding the factors influencing HCF location (Schramm, 1987). According to Browning (1993, p. 208):

Consumers of health care often lack full knowledge about the prices of different healtin care services, the quality of care offered by various providers, and the types and locations of alternative treatment products. 
This was recently supported by Salmon (1995, p. 11) "The ever-increasing ownership of health service providers, suppliers, and insurers by investor-owned enterprises presents an unforeseen complexity and diversity to health care delivery."

These issues led Beck and Dempsey (1990, p. 5) to conclude that: "This points to the fact that there is no standard cost accounting in health care, and health care services are not as price sensitive as other goods or services."

In conclusion, the health care industry has a number of distinctive aspects that appear to be different from other urban services. These include (a) the small role played by both consumers and price in determining the demand for and distribution of services; (b) the existence of several intangible social and personal externalities resistant to quantitative measurements; and (c) the relative lack of meaningful data which are fragmentally scattered among obscure private and public institutional sources.

A thorough examination of the literature can clearly identify which factors must be accounted for in the analysis of facility location; however, in a health care delivery system, these factors may vary in their effect according to HCF type. Users of UCCs are, to a certain extent, similar to some smaller HCFs such as emergency clinics or group physician clinics. Therefore, a review of factors affecting similar clinics will be used to assess which factors are suitable to UCCs in this research.

As stated earlier, there are both inter- and extraorganizational sets of factors that affect UCC location. Based on the above discussion, both sets of factors are 
highly complex. Thus this research will focus on the most important extraorganization factors. According to a review of health care literature, these factors are demographic, socioeconomic, and land use considerations.

\section{Demographic and Socioeconomic Factors}

As stated earlier, the second step for market assessment for HCF systems is to understand the demographic and socioeconomic profile of the market area (Clark and Krentz, 1991). This was supported by Hays et al., (1990), "While distance from the clinic is a powerful explanatory variable, characteristics of the patients are also important." Nauert (1992, p. 65), also supported this notion when he pointed out that:

Understanding the environment is an essential element in analyzing the competition, understanding one's constituents, and selecting the proper market niche for an alternative delivery system (ADS) . . . Descriptive and analytical studies of the environment include: 1 . Community studies; economic, demographic, and epidemiological profiles and trends of the patient population.

Geographic and demographic segmentation is an important base to the market segmentation approach. According to Kotler and Clarke (1987, p. 238): "In demographic segmentation, the market is divided into different groups on the basis of demographic variables such as age, sex, family size, employment status, income, type of health care insurance, education, religion, race, and nationality." These variables seem to encompass the most important variables influencing HCF location. 
However, for UCCs' locations, these variables will be divided into demographic and socioeconomic variables.

\section{Demographic Characteristics}

Demographic characteristics of the area under study are considered the basic elements that determine the use of health care (Harrel and Fors, 1985; Wotruba et al., 1985; Kovner, 1990; Dolinsky and Kaputa, 1990; Cokelez and Peacock, 1993; Heischmidt et al., 1993). Individuals have different frequencies of use. For instance, sex and age have been proven to influence the rate of use of HCFs (Kovner, 1990). Cashman et al., (1991a) in a study for the Health Stop Medical Management, Inc. (HSMMI), one of the nation's largest chain of UCCs, have shown that females use UCCs more than males do. Different age groups of people will normally have different needs for health care, and their usage will be different (Cashman et al., 1991a; Wotruba, 1985).

According to Nestor (1992, p. 28), "Demographic forces will be the underpinning of a further expansion in the consumers' role in choosing health services in the 1990s." This prediction is also supported by suggestions taken from the Oregon health care program and prepared by the Legislative Fiscal Office in 1993:

Demographic factors and migration trends will likely only increase the number of individuals the state assists with health care under the current set of programs and eligibility requirements. For example, the age group most likely to use the long term care program is also 
one of the fastest growing population groups in the state . . . The primary demographic trend affecting health care expenditures is the increase in the population median age (Rocco, 1993, p. 39).

Age:

Most research indicates that health care usage increases with age. Browning (1993) believes that "health care consumption rises sharply with age." Figure 2, based on the 1991 National Ambulatory Medical Care Survey (NAMCS, 1994) rate of visits to physicians' offices by age and sex, shows that the elderly make more visits to UCCs than other cohort groups.

FIGURE 2

\section{ANNUAL RATE OF VISITS TO OFFICE-BASED PHYSICIANS BY PATIENT'S AGE AND GENDER: UNITED STATES, 1991}

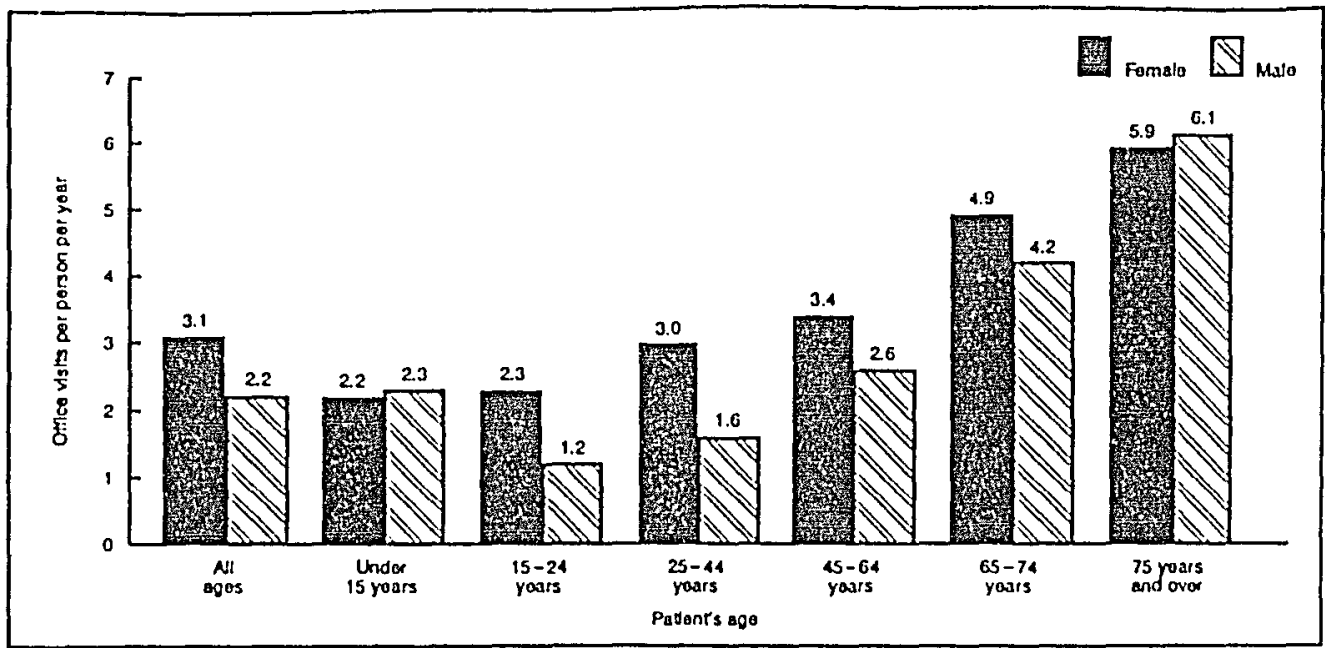

Source: The National Ambulatory Medical Care Survey: 1991 Summary. U.S. Department of Health and Human Services (1994). 
The NAMCS (1994. p. 3), 1991 survey indicated that "visit rates tended to increase with age after age of 24 . Persons 75 years of age and over had the highest visit rate of the six age categories analyzed, at 6.0 visits per person." Clark and Krentz (1991), identified age and gender as the most valuable information for estimating potential markets for HCFs. Recognizing the elderly as the major users of health care is very logical and expected. Therefore, the location of UCCs should respond to the elderly.

Phillips et al. (1994) point to the fact that the elderly population is increasing, both as a consequence of better medical care and general demographic trends. Phillips et al. (1994) concluded that technological advancements in health care combined with good habits and hygiene will reduce disease at all age levels, thus causing people to live longer. This longevity will lead to large increases in the number of elderly, which will result in greater periods of chronic disability and more use of UCCs among this group. According to Spotts and Schewe (1989, p. 36 ), the elderly population is growing "twice as fast as the general population." The U.S. population is growing, its median age is rising, and the demand for health care is increasing (Sykes, 1991; Browning, 1993). The 1990s is witnessing the aging of the baby boomers. The baby boom generation will dramatically increase the demand for health care (Plane and Rogerson, 1991; Morrill, 1993).

According to Kovner (1990, p. 126), "During 1981 the frequency of physician visits increased with age from an average 4.1 visits per year for patients under 17 years of age to 6.3 visits per year for patients 65 years of age and over." Kovner 
suggested that the increment is higher than the nation's average of 4.6 physician visits per year.

\section{Gender:}

As stated earlier, age and gender are more important than other demographic factors in estimating the HCF market. According to Wotruba (1985), age and sex have been found to be directly related to the utilization of medical services. As shown in Figure 2, and as most researchers believe, females are more frequent users of HCFs than men are. According to the NAMCS (1994) report, females made about 60 percent of all physician office visits during 1991. They also accounted for a higher percentage of visits than male did in most age categories.

Flexner and Berkowitz (1979) found that women were primarily concerned about obtaining an appointment right away. UCCs are very suitable for this "rightaway-appointment" aspect. Cashman et al. (1991a) also found that females constituted 53 percent of the total users of UCCs. Harrell and Fors (1985) claimed that women had not been targeted by either traditional and recent medical delivery systems. They suggest that the changing role of women in American society and their enrollment in the work force require providers of UCCs to enhance their accessibility. These findings suggest that women are more frequent users of UCCs than men and that providers may consider locating UCCs in areas where more women live or where they are accessible to women. 
Marital Status and Number of Children:

Lancaster and Boissoneau (1990) found an interesting difference in the demographic profile of consumers selecting a physician's office. According to their findings, consumers tended mostly to be married, older, female with one or two children under 18 years, with the head of the household holding a managerial or technical job.

The increased number of married couples in an area and family size is believed to influence HCF location. This is supported by the findings of Lumpkin and Tudor in 1990. Dant et al. (1990) found that the number and age of children in a family affects the facility choice. Clark and Krentz (1991) point out the importance of understanding the distribution of targeted populations by their family structure.

The 1980 National Medical Care Utilization and Expenditure Survey (NAMCS, 1980, p. 5 ) indicated:

Generally, a positive association can be seen between larger family size and the percent of families ever using each of the health care services (most notably, hospital inpatient care, hospital outpatient and emergency room care, and dental care.

\section{Race:}

Shannon and Dever (1974) point out that the racial composition of an area has an effect upon physicians' location preferences. In general, physicians prefer to locate in predominately white-populated areas. Shannon and Dever indicated that "physicians do avoid practice in black areas." More recently, Reisman (1993) 
pointed out that "Doctors are understandably keen to live and work in areas where the streets are safe and the amenities are good." This suggests that doctors like to locate mostly in suburban areas where research shows the predominant race is white. Cromley and Albertsen (1993) argue that suburbanization increased the concentration of poor and minority populations in the central city. This led to a 45percent decline in the number of physicians' offices in the central city from 1963 to 1980.

Chulis et al. (1993) point out that the elderly Medicare population is 89 percent white, compared to 9 percent black. This means that white elderly people have more access to HCFs and thereby use UCCs more often. However, Figure 3, based on NAMCS (1994) the 1991 survey shows that whites make more visits to HCFs than blacks do.

In conclusion, the literature clearly identifies demographic characteristics of the service area as a major factor affecting the location of UCCs. Among all demographic factors, the elderly, women, and family with children seem to be mentioned more than other factors. More attention is given to this population segment and to their rapid growth. Therefore, this study will give more attention to the elderly and their influence on UCC locations. Though previous researchers gave less attention to other factors such as sex, race, and family, the influence of those factors on UCC location will also be investigated. 
FIGURE 3

\section{ANNUAL RATE OF VISITS TO OFFICE-BASED PHYSICIANS BY PATIENT'S AGE AND RACE: UNITED STATES, 1991}

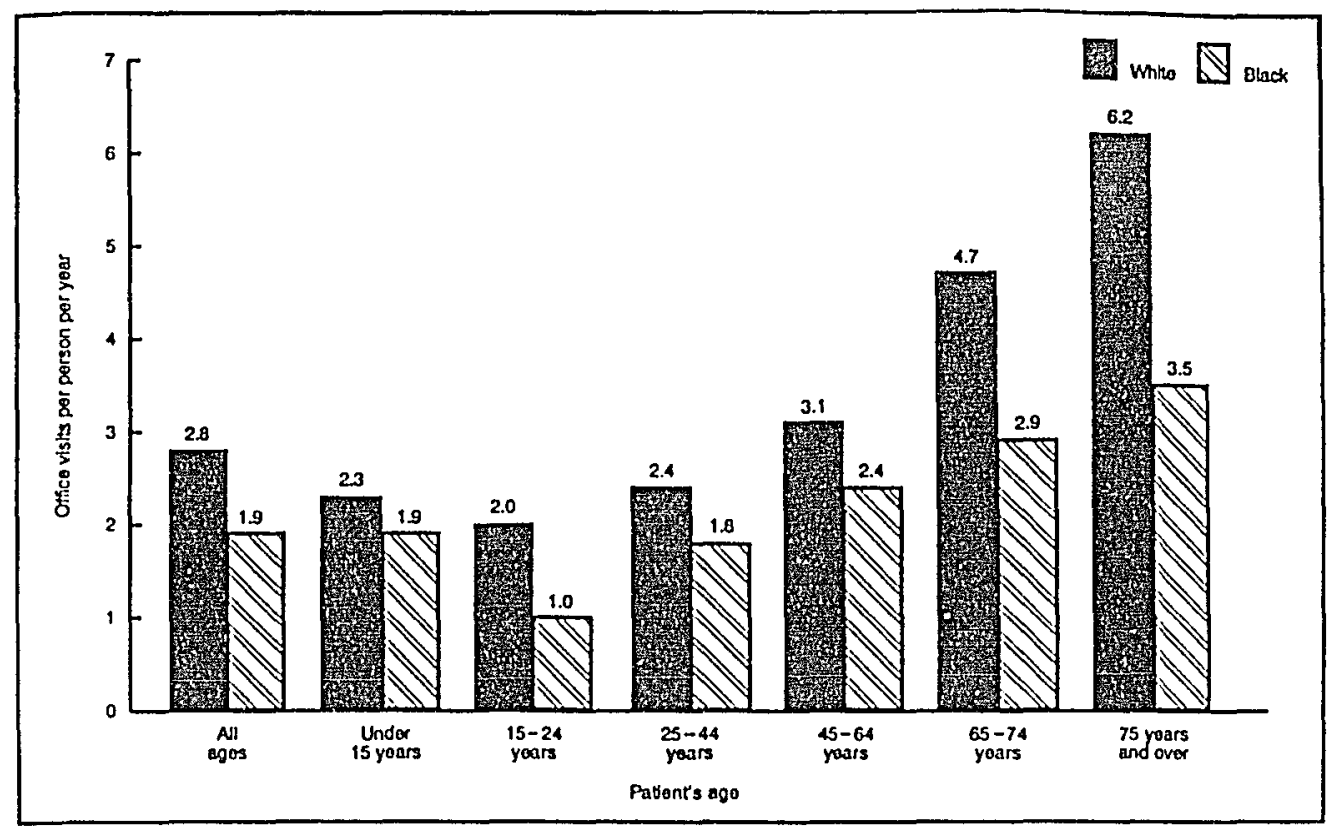

Source: The National Ambulatory Medical Care Survey: 1991 Summary. U.S. Department of Health and Human Services (1994).

\section{$\underline{\text { Socioeconomic Factors }}$}

\section{Income:}

According to Kotler and Clarke (1987), income segmentation is an old practice in health care marketing and determines whether a person is treated in a private or public facility. Earlier studies indicated that the dominant influences on physician location in the U.S. are urbanization and high per capita income (MacDowell and 
Perry, 1990). Earlier studies in upper New York state and also in metropolitan Chicago show that the relocation of physicians from central cities to the suburbs is highly correlated with economic status (Shannon and Dever, 1974). As stated earlier, providers of UCCs tend to target areas where high- and middle-income people are located. Knaap and Blohowiak (1989) studied the location of physicians in Portland, Oregon, and concluded that physicians tend to concentrate close to commercial land and high-income areas. The work of Dant et al. (1990), and Lumpkin and Tudor (1990) indicates that income is one of the important variables that affect providers' locations. Dant et al. (1990) found a positive relationship between increasing income and the use of UCCs as compared to the use of private physicians. Several authors suggest that the strongest determinants of health care provider choice were age and family income (Wotruba, 1985; Kovner, 1990; Lumpkin and Tudor, 1990; Clark and Krentz, 1991; Cromley and Albertsen, 1993).

\section{Education and Employment:}

Some researchers have recognized education and occupation as factors that providers consider when deciding where to locate HCFs (Kotler and Clarke, 1987; Schramm, 1987; Love and Lindquist, 1995; Salmon, 1995). As stated earlier, Lancaster and Boissoneau (1990) and Woodside et al. (1988), point to the fact that UCC patients tend to come from households where members hold managerial or technical jobs. Little research has been done on the effect of education and level of employment upon UCC location. However, income is believed to be highly 
correlated with both. That may explain, in part, why income is more important than other socioeconomic factors. However, being employed is more attractive to providers of UCCs, since most employers provide health insurance.

\section{Health Insurance:}

Health insurance programs have a major impact on the location of UCCs. People with some insurance policies can patronize only their affiliated hospitals. Therefore, there is a tendency for UCC users to bypass close facilities and go to their affiliated UCC location.

Reisman (1993, p. 112) suggests that "the rising income of individuals combined with tax relief extended to employers have led to an expansion of private insurers."

Figure 4 shows the escalating growth of out-of-pocket and private insurance payments in the U.S. from 1970 to 1990 . Those two forms of payments are the prime target of providers of UCCs. However, the future of UCCs may be more promising under current comprehensive health system reforms and the agreement on universal access to health care.

However, the trend to UCCs is assumed to be a marketing approach for major hospitals to diversify their customers and to reach out to the uninsured people who can afford to pay for the service (Mick et al., 1990; Salmon, 1995). According to Mick et al (1990, p. 54) there is "an increased emphasis on running health care as a business rather than a social service, including not only increases in business 
practice per se but also adaptation of symbols and language associated with business."

\section{FIGURE 4}

\section{OUTPATIENT PAYMENTS BY SOURCE TYPE.}

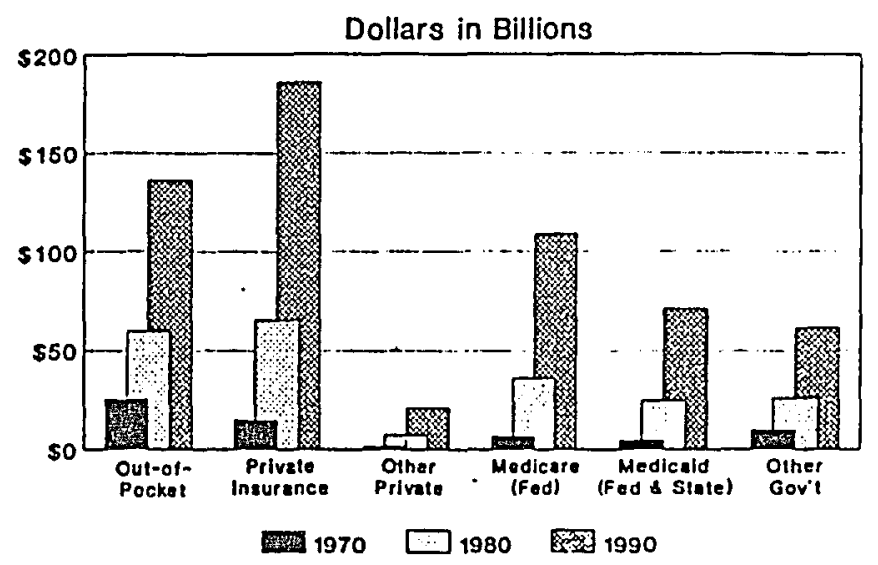

Source: A Review of State Health Care Program Costs. State of Oregon (Rocco, 1993, p. 4)

As OHS 1991 shows, there is a tendency for these UCCs to contract directly with businesses and also to accept other insurance plans. Providers of UCCs in Portland try to get more contracts with employers to attract families who are new to the area, those who have relocated within the area, or patients dissatisfied with their current provider. The above discussion clearly shows that there is a potential market for these newly evolving UCCs. Given their market-oriented aspect, these 
market niches will create more competition and will augment the growth of UCCs. This also suggests that both insured and uninsured populations are targets for UCCs. Data on the number of insured population are important for the analysis of most HCFs. However, due to the fact that these data are unavailable, income and employment may be considered as a proxy measure for health insurance.

\section{Competition}

Faced with financial distress in the late 1980s, many hospitals and multihospital systems established UCCs that could improve their capital financing (MacDowell and Perry, 1990; Burns, 1991). MacDowell and Perry (1990, p.68) pointed out that hospitals have shown more interest in changing to UCCs primarily to "increase market share and preempt expansion of competitive facilities."

Federal legislative changes enacted in the 1980s established price competition among providers of health care. According to Zwanziger et al., (1994, p. 424):

Under selective contracting, hospitals compete among themselves for contracts with health maintenance organizations (HMOs) and preferred provider organizations (PPOs) in order to obtain plan subscribers as patients ... In such physician-dominated markets, hospitals compete for patients largely through efforts to attract physicians. Referral patterns in these markets are the critical determinant of a hospital's market share.

After-hours HMO service is offered to provide subscribers with non-acute care during evenings and weekends. Due to the rapidly growing managed-care population, HMOs' demand for after-hours services seems to be an advantage to 
private UCC providers in getting more contracts with HMOs to provide this service. This will increase the demand and growth of UCCs. According to Nauert (1992, p. 64): "All of these systems were designed to capture specific market niches in ways that provide higher consumer satisfaction for the patient and more profits for the provider."

However, state licensing and land use regulation has been less stringent for urgent care than for inpatient care. This decreased regulation meant fewer barriers to entry to the market. This reduces start-up costs for new entrants to the market and makes it risky for existing providers of urgent care to face new competitors (Burns, 1990).

According to Zwanziger et al. (1994, p. 423):

Competitive dynamics in hospital care are shaped by the parties to the transaction, namely the physician, the patient, and the insurer. Each player has different criteria for selecting or guiding the selection of a hospital. The nature of hospital competition within a market depends on each party's relative ability to influence this choice.

The above discussion clearly suggests that competition is mostly an interorganizational factor which is hard to determine. However, as an extraorganizational factor, competition may be determined by considering the $\because$ locational pattern of each provider. This study defines competition by considering how close the locations of each provider are to each other. 


\section{Land Use Factors}

An essential step in planning, designing and locating HCFs is to follow planning laws pertaining to local or county land use and zoning regulations. Providers have to make sure that the location they choose for their UCC is properly zoned for such business activity. Other factors to consider include regulations on business signs and parking at the location.

The availability of commercially zoned land has also been shown to influence the suitability of an area for establishing physicians' offices (Cromley and Albertsen, 1993). Knapp and Blohowiak (1989) classified commercial zoning and income as the most influential determinants of physicians' locations.

Nevertheless, forces arising from restructuring the nation's urban areas and from encouraging the dispersal of office locations are also at work. On the supply side, land use regulations frequently prohibit establishment of offices in bedroom communities or severely limit the availability of sites.

Traffic volume and accessibility are considered factors influencing UCC location. Most providers of UCCs are located in areas of high traffic volume and are close to major arterials or highways. More discussion of accessibility will be provided in the next section.

\section{Economies of Scale}

Little has been stated in health care literature about the influence of other economies of agglomeration, economies of scale and external economies. 
Economies of scale exist if the cost per visit or other units of service decreases as the size of the UCC increases (Burns, 1991). According to the classical work of Weber in industrial locations and Isard-based minimum-cost facility locations, the location of UCCs may be influenced by these types of economies. Agglomeration economics are the advantages of locating facilities and services together in clustered form (King, 1984). Thus, some UCCs may locate to be close to the main hospital or medical facilities and services (King, 1984; Ghosh and Rushton, 1987; Chapman, 1991). This study argues that such economies of scale should be introduced to the analysis of UCC location. The availability of practitioners' offices and medical services are considered advantages for UCC to locate near. However, the presence of hospitals owned by competing providers may discourage providers to locate in such areas.

\section{Accessibility and Consumer Behavior}

In most health care literature, access to health care is considered on economic bases, such as the ability to pay for the use of health care services. However, accessibility is viewed in planning and regional science as the geographical accessibility to health care facilities. Therefore, accessibility in this study pertains to geographic or physical accessibility, measured by the distance of travel to get health care service.

While location theory suggests that consumers will travel to the nearest facility to get service, this assumption has been gradually rejected by geographic studies of 
consumer behavior. Consumers tend to make trips beyond the nearest center that has the service they need and go to the next center (Isard, 1965; Alonso, 1965; Berry, 1967; King, 1984).

Recent studies, especially on consumer shopping behavior, have shown that facility attractions such as size, quality, and agglomeration of facilities have served as reasons for some facilities to gain others' customers. Thus, some HCFs may have the drawing power to affect the consumer's pattern of use for their nearby facilities. This phenomenon has been recently supported by Hays et al. (1991). Consequently, consumer behavior and facility attraction are complementary factors.

Consumer travel patterns and behavior are highly influenced by facility attractiveness; however, facility attraction is difficult to measure. Consumers have different preferences and different valuations for services. Nevertheless, assessing individual preferences for any service depends on their evaluation and perception of the quantity or quality of health care they receive.

As stated earlier, health insurance companies often make consumers bypass close facilities and go to their affiliated UCC location. Moreover, the health care benefit typically is too highly technical for the lay person to use to distinguish among alternative health facilities. According to Browning (1993, p. 208), "Consumers of health care often lack the knowledge about the prices of different health care services, the quality of care offered by various providers, and the types and location of alternative treatment product."

Thus, people's willingness to pay for one unit of health output is deemed hard 
to quantify (Hardon, 1991). However, Day (1973) has illustrated that consumer behavior can only be comprehended by a considerably more complex theoretical structure than the traditional central place theory.

\section{Accessibility and Convenience of UCC}

Accessibility is a major variable in the effort to predict patients' behavior relative to health care services. According to Joseph and Bantock (1982, p. 85), "It's an issue of considerable importance within any consideration of the effectiveness of health care delivery." Gesler and Meade (1988) studied the roles of relative location, distance, population characteristics, and daily-activity spaces as they pertain to available HCFs. The literature reveals that physical distance is not the only factor that determines whether or not patients will use an HCF. Insurance status, income, education, occupation, age, gender, and individual preferences all have roles in this determination.

In health care literature, the relative importance of distance is measured in two ways. First, the effect of distance on use or accessibility in relation to other variables such as age, gender, and race is measured. Second, the relative importance of distance compared to the health care service received from all available alternatives is determined (Gesler and Meade, 1988; Thorpe and Brecher, 1989). However, the importance of distance is reflected on the distance decay effect on utilizing HCFs. Accordingly, the utilization of clinics decreases as distance increases from a residence to the closest clinic (Gesler and Meade, 1988). 
Joseph and Bantock (1982) indicated that there are two basic approaches to measuring accessibility to HCFs: The first is "the measurement of potential accessibility based upon the location of population relative to that of physicians." The second is distance decay analyses of utilization data. Joseph and Bantock, concluded that the former approach "focuses upon the physical or geographical accessibility of the population" to physicians and thus is much more specific than the latter approach.

Recently, Love and Lindquist (1995) studied the accessibility of heavy users to HCFs. They suggested two policy concerns regarding the distribution of HCFs in relation to heavy users: the first is whether the physical proximity to hospitals is close enough so that access is not an impediment (i.e., there is "potential" for access). The second issue is whether medical services are overburdened in those communities that have a disproportionately large population of any segment (e.g., women or the elderly).

According to Love and Lindquist (1995, p. 633), "Potential accessibility refers to the locational relationship between service providers (hospitals) and surrounding populations."

Several accessibility measures have been suggested and critiqued in planning and medical geography (Mayhew, 1986; Love and Lindquist, 1995). These measures will be discussed further in Chapter III, as they are an essential part of this study's analysis.

According to Tkocz and Kristensen (1994, p. 1), "In any urban center the 
commuting distance is a function of the spatial structure of the center and the characteristics of the commuters." Consumers' movement behavior in space is strongly shaped by the way transportation costs and the time spent per trip change. Consumers are left out today by mode-of-transportation choices that make it difficult for them to decide which option to use.

Due to limited practical alternatives, this research will use an adjacency measure for each census tract in the study area weighted by demographic and socioeconomic characteristics of each census tract. This measure will represent a significant improvement, in two respects, over previous measures. First, it is more representative of physical accessibility measures that incorporate weighted distance from each census tract centroid to all other tracts in their calculations. Second, accessibility values are calculated for disaggregated units which can easily be aggregated to the largest units of analysis deemed necessary to future research.

\section{Summary}

The literature review reveals that HCFs differ in their attributed problems, just as they differ in their interorganizational structure, policies, and the character of delivery. Health care delivery's natural complexity was shown. This may seem an extreme example to generalize about other facility locations, but it suggests that HCFs have to be studied individually, on their own merits, and that future research in health care facility location should be devoted to a more precise measurement and refinement of the major factors discussed here. 
The discussion of estimating health service area shows that it is important to identify the geographic bounds within which they can expect to attract clients. The concept of service area is very important to include in the analysis of UCC location. For instance, when UCC is located in a small defined area, such as a census tract, the surrounding census tracts are still covered by the service.

According to Shortell et al. (1990), the shift in health care was to encourage lower-cost, out-of-hospital treatments, greater competition, and alternative revenue sources. Mike et al. (1990) point to the fact that there is an increased emphasis on running health care as a business rather than as a social service.

The definition of UCCs and the forces behind their development clearly identify UCCs as market-oriented facilities, which are rapidly growing. Although UCCs are connected to major hospitals, they are still very flexible in selecting or accepting non-affiliated patients. Two motives for their development are to fill a gap in the uninsured patient market and to attract more users. Attracting more users is beneficial to revenue and induces more referrals to the main hospital. This aspect of UCC departs from the complexity of other HCFs into something more like marketing service or, as Lowell-Smith suggested, "an adaptation of modern business practice." This means, to a certain extent, that UCCs can be treated, according to location theory, as commercial facilities which locate in the best places to cater to both insured and uninsured patients.

The literature clearly identifies demographic, socioeconomic and land use factors as the crucial elements affecting UCC location. It does not reveal which 
factors have the major influence, but does, to a certain degree, show that demographic factors surely play an important role in deciding the location of UCCs. Among demographic factors, the elderly received a lot of attention, and the literature suggests they are the major factor to consider to enhance their accessibility to UCC locations. Number of children in the family, gender, and race were of less importance than age. However, number of children in the family and gender, especially women, received more attention than race.

Socioeconomic factors seem to be less important than demographic factors in influencing UCC location. However, among these socioeconomic factors, income was more important than other socioeconomic factors such as education, employment, health status and insurance. This is due to the fact that income has a very strong correlation with the above variables.

In contrast with other economic facilities, land use factors seem to have received little mention in the health care literature. This may suggest that either they are not of major concern to UCC providers, or they were not researched properly. However, this study argues that economies of scale, volume of traffic, and commercial and office concentration in the service area do have some effect on a provider's decision to locate a UCC. In addition, this study suggests that there are other factors which may affect the location decision for UCC. One of these factors is a preference to locate in areas where there are high levels of urban growth. Providers may choose to locate in these areas because they are prime sources of steady growth. 
Finally, the discussion of accessibility shows the different approaches of measuring potential accessibility of UCCs by patients. The discussion suggested the use of a more appropriate measure of potential accessibility. More discussion of this measure as an essential part of the analysis is provided in the next chapter, Chapter III. 


\section{CHAPTER III}

\section{METHODOLOGY}

This chapter presents, in two parts, the methodological framework for this study. The first part examines suitable approaches used for such analysis. The second part, research design, begins by defining the problem and the study's scope and sample. It also presents the research question, hypotheses, model, different measures of accessibility, and the data collection stage.

\section{Approaches to Examining Location Factors}

The relation between demographic, socioeconomic, and land use factors with respect to facility location have been well researched for most economic activities. However, for HCFs, research has focused mostly on spatial accessibility and methods of enhancing accessibility to HCFs. As stated earlier, these methods include service area delineation, spatial interaction models, and optimization techniques for the optimal location of HCFs. HCFs have been, in general, the focus of most of these studies. Little work has been done studying the relation between the above factors and UCC location. This work is carried out in the field of market research for UCCs. Market research approaches focus on consumer choice for selecting UCCs, rather than on the provider's choice of location. 
There is no prior research examining the relationship between the location of UCCs and the factors affecting their location; however, there are several approaches for studying the major factors affecting HCF location in general. Given that UCCs as facilities have almost the same function as other HCFs, these approaches can also be used for studying UCCs. The literature review of these approaches include correlation, discriminant analysis, regression, and discrete choice analysis.

Recently Lowell-Smith (1993) studied the "regional and intrametropolitan differences in the location of freestanding ambulatory surgery centers (FASCs)" in the U.S. She used a Spearman's rank-order correlation to study the relationship between population distribution and FASC locations in the U.S. She used the location quotient to measure the degree of concentration of FASCs.

Correlation analysis is used mostly to assess the degree of association among several independent variables (IVs) on the dependent variable (DV) and the direction of the covariation. Correlation analysis is not suitable to explain or predict the additive effect of each IV on the DV, or to reflect the degree to which the magnitude of changes in one set of data is associated with comparable changes in the other set (Sirkin, 1995).

Discriminant analysis (DA) is superior to correlation analysis in the way it determines which variables maximally discriminate among some predefined groups. For example, it can be used here to determine which variables are important discriminants of areas with and without UCCs. In addition DA is useful in predicting the discriminatory power of each variable. DA is used mostly in clinical 
psychology and biology. Conceptually, DA is analogous to multiple regression, however, it becomes more complicated when used with more than two groups or when several variables are involved (Chatfield and Collins, 1980; Dunteman, 1984; Clark and Hosking, 1986; Stevens, 1992). However, in this study the assumptions of multivariate normality among the predictors may not be met due to the inclusion of dichotomous variables (e.g., volume of traffic). Second, and more importantly, the variance-covariance matrices for the classification groups of census tracts which have UCCs or not differs dramatically. Given these violations of the distributional assumptions, along with the unequal group sizes, the results of the discriminant analysis will clearly be biased to some unknown extent (Stevens, 1992, p. 258; see Appendix $\mathrm{C}$ for more details). In contrast, the logit analysis discussed later is not affected by these violations.

Regression analysis is also a major improvement over correlation analysis. Regression analysis is a statistical technique that not only assesses the strength of the relationship between the DV and IVs, but also explains and predicts the independent effect of each IV on each DV separately. It assesses the effect of a particular IV by controlling for the influence of other IVs in the analysis (LewisBeck, 1980; Babbie, 1983; Clark and Hosking, 1986).

Regression analysis is a popular standard statistical tool that is widely available in computer packages and easy to interpret. It remains a highly reasonable method even if some of its underlying assumptions are not met in the data. However, failing to meet some of the regression assumptions may lead to quite unreasonable 
estimates. Such is the case when the dependent variable is a binary (dichotomous) variable rather than a continuous variable. In this case regression estimates with a binary dependent variable "can lead to serious errors in inference" (Aldrich, 1984).

The failure of regression analysis with binary dependent variables is particularly troubling when the underlying interest is to study the choice of locating UCCs, which is a binary variable of either locate or not. What is needed, therefore, is a more advanced technique that can do the work of regression analysis but is not sensitive to the presence of a binary dependent variable. Such an advanced technique is available through the utilization of discrete choice analysis, probability logit or probit models.

Among the most suitable approaches to this problem is the use of discrete choice analysis. Discrete choice analysis has long been of interest to researchers in several fields. According to Ben-Akiva and Lerman (1985), the origins of probabilistic choice models are in mathematical psychology. However the authors cited several references for the application of discrete choice analysis in other fields.

A special approach in linear probability or discrete choice analysis is the binary probit and logit analysis. The logit model is assumed to be "more convenient analytically" than the probit model (Ben-Akiva and Lerman, 1985). The logit model computes the probability of an area either having or not having a UCC depending on a given set of IVs. The great strength in a logit model is being able to get an idea of predictability. According to Liao (1994, p. 6), a common characteristic for all generalized linear models is that "each estimate gives the 
partial effect of a coefficient with the effects of other $x$ variables being controlled." Most researchers dealing with binary DVs often use logistic regression models (Agresti, 1990; Steven, 1992). The logit model is commonly used in cases where research questions involve group differences (Hardy, 1993). According to Cramer (1991, p.1):

The logit model is the natural complement of the regression model . . . but unlike regression, the logit model permits use of a specific economic interpretation in terms of utility maximization in situations of discrete choice.

Cramer also emphasized the fact that logit models are used frequently in other fields beside the discrete choice analysis. He concluded:

Together with other probability models for qualitative dependent variable, the logit model has its origins in the analysis of biological experiments. The class of phenomena and models we have thus loosely defined is variously denoted in the biological literature as quantal variables or as stimulus and response models, in econometrics as qualitative or limited variables, and in psychology and economics as discrete choice (Cramer, 1991, p. 5).

Discrete choice analysis is mostly used to study consumer behavior rather than provider's choice to locate UCC. However, the basic assumptions of the logit models would not be violated when used to study provider's choice of locating UCCs. The logit model can be conceptualized as a location choice model of provider behavior but, without client propriety data, the public data can be used to explain in a binary regression model the location pattern of UCCs.

The logit model is the most suitable approach for this study of UCC location 
since the study requires a discrete choice of locating a UCC between two sets of service areas. Typical regression analysis does not provide such a probability choice.

\section{RESEARCH DESIGN}

\section{Statement of the Problem}

For planners and health care providers, the problems encountered in locating UCCs are very complex by their nature and involve several factors which have varying effects. For health care providers, however, the decision to locate UCCs may be more political than economic. Vested interests on the part of influential physicians and management may cloud the issue of location decisions. These issues need to be addressed and evaluated in the context of the organization's overall strategic needs. Nevertheless, this study focuses on the location outcomes rather than on the extraorganization issues. In essence, the aim is to explain UCC location in terms of consumer accessibility; some of the unexplained variation may be attributed to some extraorganization factors which are beyond the scope of this study. In order to focus the reader's attention, a restatement of the problem is provided below.

At the beginning of this study, little information or data were made available by providers of UCCs in Portland. The secrecy and lack of coordination of information made it more difficult to understand each provider's policies or objectives and clearly confirms that planning and expanding of UCCs in Portland is 
done without consideration of other providers' locations.

The specific problem targeted in this research is to use publicly available data to evaluate and determine the factors influencing UCC locations. We assume that the providers of UCCs locate their facilities based on some knowledge of their existing clients. Due to the lack of access to providers' propriety data this study uses public data as a proxy for providers' data. The essence of this research is to find out how well this publicly available data explains UCC providers' location behavior.

Meanwhile, the demographic and socioeconomic profile of Portland is changing. As stated earlier, Portland is experiencing changes in the age composition of its population, with a marked upward trend in the number of elderly. Overall growth of the elderly population in Portland is higher than in most cities in the nation. But have providers of these newly evolving UCCs selected their locations in response to these changes in what Kassaye and Tseng (1990) called "the macro-environment" -- a "demographic, economic, and to a limited extent, competitive environment?" In fact, health services providers have responded to these changes by developing integrated health care systems, separating from hospitals, and developing physician-hospital organizations (Toso and Farmer, 1994). However, relating this development effort to the characteristics of UCC locations is not well understood and seems to be neglected as an important element in deciding how to target heavy users.

Understanding these factors is crucial to explaining why UCCs cluster in 
certain urban areas, while other areas are under serviced. It is also important for UCC providers who want to enhance accessibility of special population segments to their UCCs. Accordingly, UCC locations should attract special population segments by maximizing accessibility to UCC locations. The literature on the location of other HCFs clearly suggest that demographic, socioeconomic and land use factors are the major influences on UCC location. This research examines the relationship between existing UCCs' locations and the above factors. In essence, it is intended to show how these factors explain and predict existing locations of UCCs. The aim is to find out whether existing patterns of UCC locations are representative of what the literature suggests, and to understand the aggregate location behavior of UCC providers.

\section{$\underline{\text { Research Questions }}$}

The research question is: Which factors of the demographic, socioeconomic, and land use factors account for the location of existing UCCs? It is important to determine the array of factors affecting UCC location before answering the research question. Therefore, the previous literature review was intended to provide clear determination of these factors. In essence, the research questions are: Why are UCCs located where they are now? Are the existing service areas of UCCs following a pattern which is representative of what prior research suggests?

\section{Research Hypotheses}

The analysis examines several hypotheses concerning the factors that affect 
UCC locations in urban areas. The main research hypothesis is that the existing locations of UCCs are influenced by demographic, socioeconomic, and land use factors. This is supported by the literature review presented in Chapter II. The literature suggest that demographic and socioeconomic factors have varying influence on UCC location in urban areas. These factors are assumed to be a priority in the providers' agendas. In addition, this study argues that land use factors are also important contributors to UCC location. Therefore, this study has three subhypotheses which are:

\section{$\mathrm{H}_{1}$ Demographic factors of the service area are the major determinants of UCC location in urban areas.}

This hypothesis is supported by previous literature suggestions that UCCs will most likely locate close to areas characterized by high percentages of elderly, females, whites, and families with children.

$\mathrm{H}_{2}$ Socioeconomic factors of the service area affect the location of UCCs.

As mentioned in the literature review, UCCs are most likely to locate close to areas of higher socioeconomic status such as high income, professionals, and medically insured households. As stated earlier, this study used income as a proxy for other socioeconomic factors.

$\mathrm{H}_{3}$ Land use factors affect the decision to locate UCCs in urban areas. As mentioned in the literature review, prior research on other economic facility 
locations suggests that UCC location is most likely to be close to areas with high volume of traffic, growth, commercial and office space zoning, economies of scale, and competition.

\section{Study Scope and Sample}

In order to answer the research questions above, a practical case was tested. The project is a case study of Portland, Oregon. There are several UCC providers in Portland. Each provider has a different distribution pattern, and some tend to locate adjacent to their competitors.

Most UCC providers are private organizations that compete with each other to attract patients. This competition has led to an uneven distribution of UCCs in the metropolitan area. Figure 1 (presented in Chapter II) shows that some areas are over supplied, while others are underserved.

Portland was chosen because it is one of the fastest growing metropolitan areas in the U.S. During the last decade, it witnessed a steadily rising economic and population growth greater than most areas in the U.S. Such growth is predicted to affect the population distribution in Portland with respect to accessibility to existing inventory of health care facilities. This population change makes Portland a unique case.

Demographic aspects: Portland is the major city in the state of Oregon, which, as a state, has a unique demographic pattern in its elderly population. The elderly are assumed to be the most frequent consumers of health care because they benefit 
from the Medicare program. Elderly people (over 65 years of age) in the state of Oregon comprised $14 \%$ of the total population in 1990 . This is higher than the national average of $11 \%$. Oregon's better-than-average quality of life will likely cause the percentage of elderly to continue rising within the state. By the year 2030 , the elderly population is expected to reach 20 percent of the population of Oregon. The growth of the elderly population segment in Oregon was 31.3 percent during the 1980 s, while average state population growth was only 8.1 percent. Oregon also has a homogeneous elderly population: in 1990, 97 percent of the elderly population was white (CPRC, 1994).

Portland is an example of those cities where the growth of managed care is overwhelming. The growth of managed care is believed to induce more utilization and growth of UCCs in the city, thereby making it more interesting to study.

\section{The Study Area}

The study area of Portland is divided into 275 CTs as presented in Figure 5. The population of each CT is served by nearby UCCs. Given the inventory of UCCs shown in Figure 5, it is clear that some CTs are served directly while others are considerably far away from these UCC locations. Therefore, people have varying accessibility to UCCs in Portland. This means that there is an uneven distribution pattern of existing UCCs in relation to population locations.

\section{$\underline{\text { Research Model }}$}

The location for UCCs can be determined by considering travel distance over a 
FIGURE 5

MAP OF THE STUDY AREA OF THE TRI-COUNTIES OF PORTLAND,

OREGON, 1990

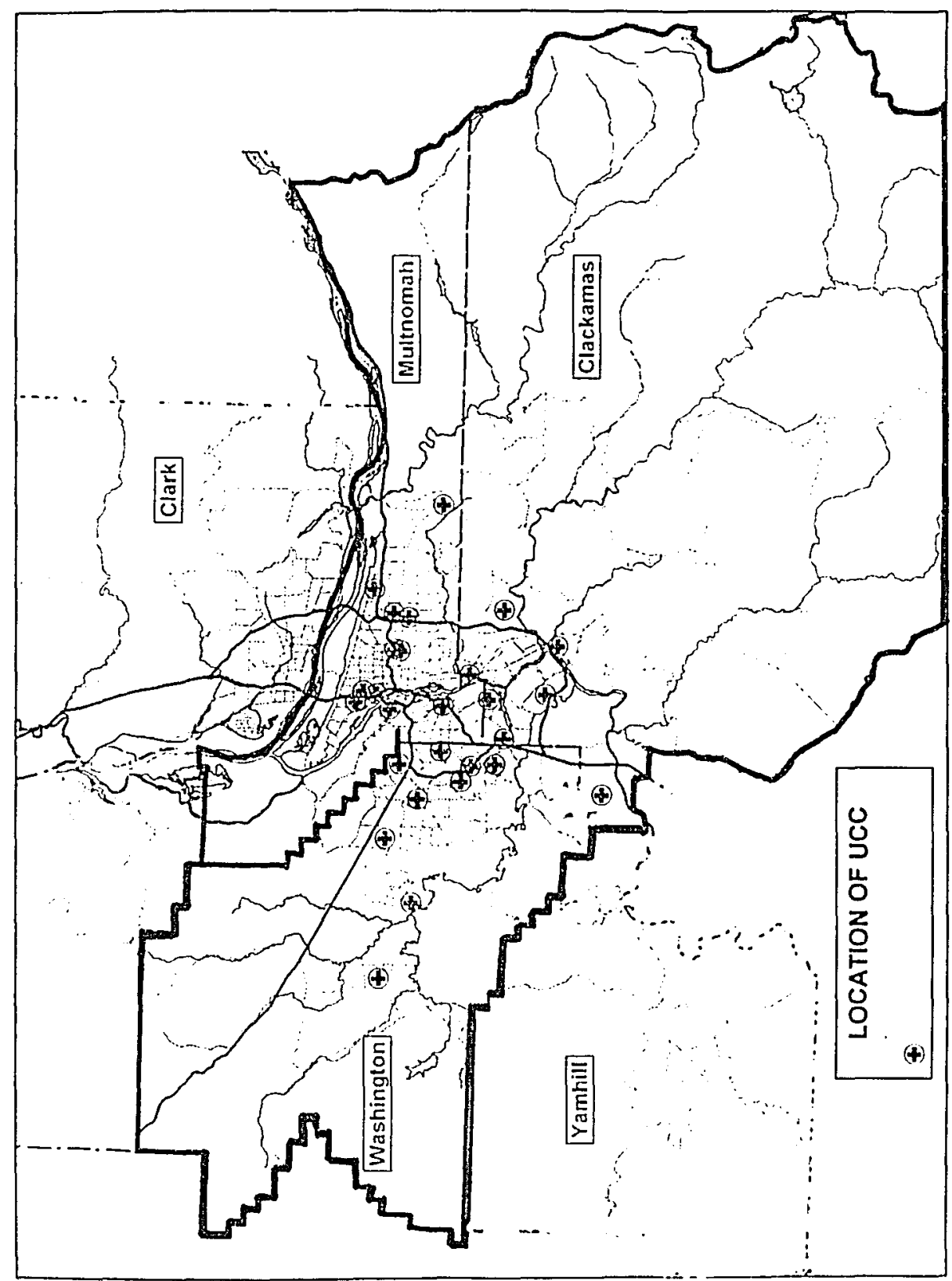

Source: Produced by an application of address matching using GIS. 
network on which demand points and UCCs are located. Consumers to be served are at $(n)$ locations, which we call demand points $(i=1, \ldots, n)$ and are represented by the centriod of each census tract (CT) covered in the service area. The location of each demand point is given by the coordinates $\mathrm{Xi}$ and $\mathrm{Yi}$. In addition, each of these points is associated with a different demand weight (Wi). The weight at each demand point is related to the measure of the effect of each factor at each demand point.

Since the Portland metropolitan area has a large number of demand points spread widely across the entire area, a system of service areas will be used. All the demand weight can be assumed to be at the centroid of each CT. UCCs are located close to the centroid of each service area to serve surrounding demand points.

The general model of this study is a logit model. It uses log-odds (L), that a CT has a UCC, as the dependent variable which is a function of several independent variables. The model will explain the likelihood that a CT will or will not have a UCC depending on the effect of the different IVs included in the wright side of the model. The formula for the logit model is:

$$
\mathrm{L}(\mathrm{UCC})_{\mathrm{i}}=\mathrm{f}\left(\sum_{\mathrm{j}} \mathrm{A}_{\mathrm{ij}} \mathrm{I}, \boldsymbol{\Sigma}_{\mathrm{j}} \mathrm{A}_{\mathrm{ij}} \mathrm{E}, \boldsymbol{\Sigma}_{\mathrm{j}} \mathrm{A}_{\mathrm{ij}} \mathrm{S}, \boldsymbol{\Sigma}_{\mathrm{j}} \mathrm{A}_{\mathrm{ij}} \mathrm{W}, \boldsymbol{\Sigma}_{\mathrm{j}} \mathrm{A}_{\mathrm{ij}} \mathrm{CH}, \mathrm{V}, \mathrm{O}, \mathrm{H}, \mathrm{EC}, \mathrm{C}, \mathrm{G}\right)
$$

Where:

L : The probability whether there is UCC in CT or not. Dummy variable with values of 0 or 1 . 
$\mathrm{n}$

$\boldsymbol{\Sigma}_{\mathrm{j=1}} \mathbf{A}_{\mathrm{ij}}$ : Adjacency of CTs with households with income (I) over $\$ 35,000$, elderly

(E) over 65, females (S), whites (W), and children in thefamily (CH). Adjacency is measured the product of the population of each CT by an adjacency matrix of value as 1 for adjacent $\mathrm{CT}$, or otherwise. The adjacency score of $A_{i j}$ is weighted by one variable $(I, E, S, W, C H)$ at a time

I : Number of families with annual income over $\$ 35,000$ in each CT.

E : Number of elderly (over 65) group in CT.

S : $\quad$ Number of women in each CT.

W : Number of whites in each CT.

Ch: Number of children in each CT.

V : Presence of a highway with volume between $20,000-40,000$ vehicles per day in each CT. Dummy variable $(0,1)$.

$\mathrm{O}$ : Presence of high number of office or retail employment in each CT.

H: Presence of a hospital in the each CT or adjacent CTs, dummy variable $(0,1)$.

EC: Presence of economies of scale in each CT or adjacent CTs as measured by the numberof group practitioners and medical facilities; dummy variable.

C : Presence of other competitors in the same or adjacent CTs; dummy variable $(0,1)$.

G: building permit increments for the last five years in each CT. 
Demographic and socioeconomic data are included in the data base for this model to explore and to be able to identify which one or more of these variables improve the fit of the model.

The logit model is primary used to test the research hypotheses. As stated earlier, prior research for studying the additive effect of each variable in each model suggests the use of the logit model. It is one of the most powerful techniques for isolating the independent effects of each variable when the outcome variable is dichotomous (Stevens, 1992; Aldrich and Nelson, 1984; Norusis, 1993a). This aspect makes it easier to examine simultaneously the major variables that have greater influence on UCC location in urban areas. The model specification is very important for logistic regression analyses. Therefore, great consideration was given to measurement of variables and their colinearity.

\section{Accessibility to Existing Urgent Care Centers in Portland, Oregon}

Current and future aggregate demand for traditional medical facilities by each demographic segment, i.e., elderly, females, etc., were extensively researched for most cities in the U.S. Unfortunately, little has been done in this regard to these demographic segments in Portland. However, prior research suggests that some demographic segments of the population are underserved while others are overserved. Given this uneven geographic accessibility to UCCs in general suggests the need to study the accessibility of each major demographic segment to nearby UCCs. 
A variety of geographical accessibility measures have been suggested and discussed in the literature. As stated earlier, these measures range from a simple measure of distance between facility and population served, to more sophisticated spatial interaction models (Goodchild and Noronha, 1983; Ghosh and Rushton, 1987; Ghosh and McLafferty, 1987; D’Amico et al., 1994). Table I presents some alternative accessibility measures which have been commonly used.

\section{TABLE I}

\section{ALTERNATIVE ACCESSIBILITY MEASURES}

\begin{tabular}{||l|l|l|}
\hline Accessibility measure (A) & Formula & Description \\
\hline Choice-set & $a_{i}=(y)$ & $\begin{array}{l}\text { Number of UCCs within } \\
\text { a distance of y miles } \\
\text { from area i. }\end{array}$ \\
\hline Shortest distance & $a_{i}=\min \left(d_{i j}, v_{j}\right)$ & $\begin{array}{l}\text { Distance to hospital } \\
\text { closest to area i. }\end{array}$ \\
\hline Mean distance & $a_{i}=\Sigma q i j d i j$ & $\begin{array}{l}\text { Average weighted } \\
\text { distance of population to } \\
\text { each nearby UCC. }\end{array}$ \\
\hline Hansen measure & $a i=\Sigma A_{j} \exp \left(-b d_{i j}\right)$ & $\begin{array}{l}\text { Measure of the attraction } \\
\text { of UCC based on } \\
\text { measures of attraction } \\
\text { and propensity of travel } \\
\text { to UCC. }\end{array}$ \\
\hline Log-sum measure & $\begin{array}{l}a_{i}=(1 / b)\left(\operatorname{Lx} \Sigma A_{j}\right. \\
\left.\exp \left(-b d_{i j}\right\}\right)\end{array}$ & $\begin{array}{l}\text { Similar to Hansen } \\
\text { measure with log } \\
\text { adjustments. }\end{array}$ \\
\hline
\end{tabular}

Source: Adapted from Love and Lindquist (1995) 
According to Love and Lindquist (1995), the first two accessibility measures, choice-set and shortest distance have several advantages. These advantages include being efficient, conceptually simple, and more intuitive to interpret. Nevertheless, in this case study, the data required to calculate accessibility based on the above described measures are not readily available. Therefore, this study will use an adjacency matrix measure as a proxy to accessibility measure. More discussion of this adjacency matrix is provided in the methodology chapter of this study.

\section{Data Sources and Variable Measurements}

This study uses the 1990 cross-sectional analysis by using three sets of secondary and firsthand data. For the first part, the model uses secondary data provided by the 1990 census tract (CT) demographic and socioeconomic data for Portland's tri-counties; Multnomah, Washington, and Clackamas. Two hundred seventy-three CTs of the PMSA represent the study area and are the UOA for this study. CT was chosen not only because it will give more of a desegregate level of analysis, but also because accessibility data needed for the study are available for such unit of analysis. This data is useful for measuring distances between demand points and UCCs to devise the accessibility measure index.

The second set of data is collected for the land use variables. These data were gathered from different public and private agencies and through published reports. Volume of traffic was calculated based on transposing a plot of the 1990 p.m. peak (4:30 to 5:30 p.m.) auto volumes on a CT's map for the Portland metropolitan area. 
This transposing allows us to determine the CTs with high volume of traffic. This data was based on the transformation of traffic analyses zones (TAZ), provided by Metro of Portland, into CTs. Metro of Portland is responsible for providing regional policies based on its land use, transportation, and socioeconomic data bank. TAZ to CT equivalency list was made based on Metro's 1260-zone system and the 1990 CTs. The equivalency is based on a coordinate match using a GIS program called regional land information systems (RLIS), Metro's parcel-land GIS database. The volume of traffic values was calculated based on road network path by EMME/2 (transportation model).

Office and commercial areas were measured by the number of employees in each CT. This data was provided by Metro. CTs with a high amount of employment is an indicator of high percentages of office and commercial space. The number of competitors in each CT was taken from a plot of all the locations of existing UCCs on a CTs map, then each CT with more than one UCC or that has a UCC in the adjacent CT was selected as a CT with competition. The hospital variable was measured as a dummy variable from a survey of all hospitals in the Portland metropolitan area. The economies of scale variable was calculated based on a survey of all medical research facilities and major medical group practices in, or adjacent to, the CTs. As shown in the formula for the logit model, the economies of scale variable is a dummy variable of values of 0 or 1 , depending on the presence of economies of scale in, or adjacent to, the CTs. CTs which have any group practices or medical research facilities in the same CT or the adjacent CTs 
are measured as CTs which have economies of scale and will have a value of 1 , otherwise 0 . Data on growth or newly developed areas, or CTs, were collected from housing stock based on building permit activity by $\mathrm{CT}$ data provided by Metro for the last five years (1985-1990).

The third set of data is provided by results of a telephone survey conducted of all medical clinics and hospitals in the Portland tri-county area. The survey was needed to determine which clinics were meeting this study's operational definition of UCC, in 1990. Moreover, the survey was intended to verify some needed data on competition and economies of scale variables. The results of the survey are presented in the next chapter. 
CHAPTER IV

\section{URGENT CARE CENTERS IN PORTLAND, OREGON}

This chapter describes the location of existing providers of UCCs in Portland and clarifies the operational definition of a UCC as would be utilized in this research. It explains the finding of a survey of all providers of UCCs in the Portland tri-county area for the year 1990, in order to determine which UCCs are meeting the operational definition of this study, and presents some other unavailable data needed to carry out this research. Such data includes the number of competitors and economies of scale factors adjacent to existing UCCs.

\section{The Definition of Urgent Care Center}

As stated earlier, it is beyond the scope of this study to cover all types of urgent care centers in the Portland metropolitan area. Therefore, the focus of this study is UCCs, which offer general medical urgent care, including emergency treatment, for extended hours (before 9 a.m. and after 5 p.m.), without prior appointment. This operational definition is the closest to the definition suggested by the literature that a UCC is a free-standing ambulatory facility that comprises general practitioner offices and an ambulatory unit. UCCs have extended hours of operation and no appointment needed (Phillips and Reeder, 1987; Cashman et al., 
1991b; Kovner, 1990).

For the purpose of this study, a UCC is defined as an ambulatory facility which comprises one or more general practitioner offices. It should offer an extended daily hours of operation beyond the normal business hours of 9 to 5 and on weekends. Meanwhile, it must provide urgent care without the need for an appointment, and should have the necessary equipment to take care of minor illnesses and injuries. However, hospital-based UCCs which accept walk-in patients for minor injuries and illnesses, although not free-standing facilities, will be included in this study since they meet the study's definition of providing urgent care regardless of their location. However, a hospital with an emergency room is not necessarily providing urgent care. Emergency rooms meet all of this study's definition of a UCC but, in fact, are quite different facilities and are not included in this study. Further, hospitals are included to have a sufficient population sample to carry out the analysis. Therefore, the basic criteria to select the UCC that fits this study's definition are that each clinic must provide:

* general medical care;

* urgent care; by accepting walk-in, immediate, and convenient appointments. (UCCs that require advance appointments are not included in this study);

* extended hours of operation; by being open to offer medical care before 9 a.m. and after 5 p.m. on weekdays and operate variably or on-call on weekends. Any UCC that does not operate on weekends for an average of 4 hours or is only open one hour beyond the normal business hours of 9 to 5 
on weekdays are excluded from this study. For example, all UCCs that open from 8 a.m. till 6 p.m. are not included in this study; other UCCs that open before 8 a.m. and stay open after 6 p.m. are included.

* urgent care facilities and equipment. Each UCC must have the necessary urgent care facilities to carry out urgent care, such as $\mathrm{x}$-ray and laboratory facilities.

Given the above definition, this study conducted a telephone survey of all HCFs in the Portland tri-county metropolitan area. The survey included some important questions needed to verify which UCCs fit the study's definition of UCC and their exact locations. Moreover, the survey was also intended to provide some unavailable data needed for this study, such as the presence of nearby competitors or economies of scale factors. All questions were asked to represent UCCs conditions for the year 1990 .

\section{Urgent Care Centers in Portland, Oregon}

The hospital industry in Oregon is a major part of the state's economy. In 1991 hospital business revenue amounted to $\$ 2.2$ billion and employed about 30,000 full-time staff positions. Hospitals in Oregon are mostly located in the Portland metropolitan area. Between 1987 and 1991, the percent of Oregon hospital outpatient revenue increased from 24 percent to 32 percent due to the increase of 61 percent of outpatient visits (OHS, 1991). According to Oregon Hospital Statistics (1987-91) (1991, p. 4): 
Many of the changes in the way hospitals deliver service have been motivated by the changes in the payment system for health care. "Managed care" is generic term for a variety of health care payments and cost containment strategies that have become prevalent during the past decade.

\section{The Survey}

Based on the literature review and the research hypotheses, I decided to carry out a survey of all UCCs in the Portland Metropolitan area to find out which of the 1990 UCCs meets the study's definition of UCC.

As stated earlier, there are several providers of urgent care in the Portland metropolitan area and there is no clear definition of UCC. Therefore, the survey was intended to facilitate the UCC which fits the research's definition of UCC. Most UCCs in 1990 for the Portland metropolitan area have different hours of operation. Some of them require prior appointment or do not provide general medical care. In 1990, there were several providers of UCCs. Appendix A presents the survey questionnaire and a list of all providers of urgent care in the Portland metropolitan area for the year 1990. There were no available official listings of providers of urgent care in the Portland metropolitan area. Therefore, the study used the 1990-1991 U. S. West telephone directory and surveyed all medical clinics and hospitals in the Portland metropolitan area.

\section{The Questionnaire}

Given that this study presents a cross-sectional analysis for the location of UCC in the Portland metropolitan area for the year 1990, a questionnaire was designed to 
provide the necessary information about the condition of UCCs in 1990. The questions were designed to reflect reliably the conditions of 1990 and, therefore, the respondents were selected from each UCC who witnessed the operation of the clinic in 1990 or at least knew about the clinic's history.

Two steps were initially made before conducting the survey. First, all clinics that provided only specialty medical care, such as allergy, dermatology, cosmetic surgery, occupational and eyes, were omitted from the list since they do not fit the definition of general medical care. Second, all respondents to the survey were asked to answer the questions to the best of their knowledge as to what the conditions were in 1990 . The reason for this precaution was to make sure that the respondents presented the facts about the operation of the clinic in 1990 and did not contaminate or confuse the facts with the present situation in 1995 .

Some of the 1990 clinics and hospitals, which provide urgent care, are now owned by different providers. For example, Emanuel, Good Samaritan, and Meridian Park hospitals were self-owned by 1990. Now these hospitals are merged with the Legacy health care system. St. Vincent Hospital is now a part of the Sisters of Providence health system. Nevertheless, these mergers will not affect the analysis since these clinics and hospitals were still providing urgent care from the same locations as of 1990.

In 1990 there were several providers of urgent care; however the ones which fit this study's definition and criteria are shown in Table II. They include the Sisters of Providence, Legacy, Kaiser Permanente, The Portland Clinic, and Tuality as the 
major providers of UCCs in Portland. Some other major providers of UCCs, such as OHSU and other UCCs, were not providing urgent care in 1990 according to this study's definition and, therefore, were excluded from this study.

The questionnaire contained several questions which were intended to provide the following information:

1. To make sure that the UCC provided genieral care, and that the UCC has a general medicine practitioner.

2. To verify that the UCC operated on an extended hours basis to match the study operational definition of UCC.

3. and 4. To determine if the UCC accepted walk-ins and convenient admission to meet the definition criteria.

5. To make sure that the UCC could provide the urgent care required by having $\mathrm{x}$-ray and lab facilities.

The above questions were needed to facilitate the UCCs that meet the study's

definition of UCC. The rest of the questions were intended to provide some additional data needed for the measurement of the land use factors influencing UCCs location:

6. To provide the address and the location of the UCC, which is needed to locate all UCCs on a GIS map.

7. To provide information for the land use variables about the existence of competitors, medical practitioner offices and medical research or lab facilities.

8. To find out if there were any competitors' near this UCC. 
9. Additional data needed to know the owner organization of the different UCCs under study.

TABLE II

LIST OF UCCS PROVIDERS IN PORTLAND, OREGON, 1990

\begin{tabular}{||l|c|l||}
\hline Provider & $\begin{array}{c}\text { Number of } \\
\text { UCCs }\end{array}$ & Location of UCCs \\
\hline Sisters of Providence & 10 & $\begin{array}{l}\text { St. Vincent } \\
\text { Milwaukie } \\
\text { Providence } \\
\text { Mercantile } \\
\text { Tigard } \\
\text { Tanasbourne } \\
\text { Sunnyside } \\
\text { Wilsonville } \\
\text { Vermont } \\
\text { Parkrose Plaza }\end{array}$ \\
\hline Legacy & & $\begin{array}{l}\text { Emanuel } \\
\text { Good Samaritan } \\
\text { Meridian Park } \\
\text { Gresham } \\
\text { Milwaukie } \\
\text { Tigard }\end{array}$ \\
\hline Kaiser Permanente & & $\begin{array}{l}\text { Greeley } \\
\text { Sunnyside } \\
\text { Beaverton }\end{array}$ \\
\hline The Portland Clinic & 3 & $\begin{array}{l}\text { Tigard } \\
\text { Portland } \\
\text { Beaverton }\end{array}$ \\
& & $\begin{array}{l}\text { Aloha } \\
\text { Tanasbourne } \\
\text { Forest Grove }\end{array}$ \\
\hline Tuality Health Care & & $\begin{array}{l}\text { Clackamas } \\
\text { Oregon City }\end{array}$ \\
\hline & & 3 \\
\hline
\end{tabular}




\begin{tabular}{|l|c|l||}
\hline Portland Adventist Medical Center & 2 & $\begin{array}{l}\text { Portland } \\
\text { Clackamas }\end{array}$ \\
\hline Doctor's Family Clinic & 1 & Beaverton \\
\hline Metropolitan Clinic, PC & 1 & Tigard \\
\hline Beaverton Primary Care & 1 & Beaverton \\
\hline Woodland Park Hospital & 1 & Portland \\
\hline Suburban clinics & 1 & Gresham \\
\hline Lake Oswego & 1 & Lake Oswego \\
\hline North Portland Clinic & 1 & Portland \\
\hline Eastmoreland Hospital & 1 & Portland \\
\hline Mt. Tabor Clinic & 1 & S.E. Belmont \\
\hline Total & 38 & \\
\hline \hline
\end{tabular}

Source:Based on telephone survey utilizing US West 1990 Phone Directory.

\section{The Survey Results}

The results of the survey show that most urgent care providers in the Portland metropolitan area do not agree with our operational definition of "urgent care." Some of the providers will answer the no-appointment concept as immediate, convenient or same-day appointment. Similarly, for the extended hours operation, some will operate only from 9 to 5 while others will operate earlier or later than these periods. Since those concepts are very close to our definition of UCC, only 
those with extended hours of operation and that provide immediate or convenient appointment arrangements were included in this study.

The results of the survey as presented in Appendix A shows that the UCCs that met this study's definition are 38 UCCs which are presented in Table II and shown in Figure 6. All these clinics were in the same location since 1990. Three UCCs were found to be close to a competing hospital; however, none were close to their affiliated hospitals. There were 32 UCCs close to major groups of practitioners, and 17 of those were close to medical research and lab facilities. Among the UCCs under study, 19 are close to competitors, either in the same census tract or adjacent census tracts.

The descriptive data provided by this survey are an essential part of the study. The data is needed to measure the different variables in the methodology part of this study. Besides the above data are helpful in cross-verifying the results of the study. For example, the presence of medical group practitioners near 32 UCCs in this study have to show some importance for the economies of scale variables in predicting UCC location. 
FIGURE 6

MAP FOR THE LOCATIONS OF URGENT CARE CENTERS IN PORTLAND, OREGON, 1990

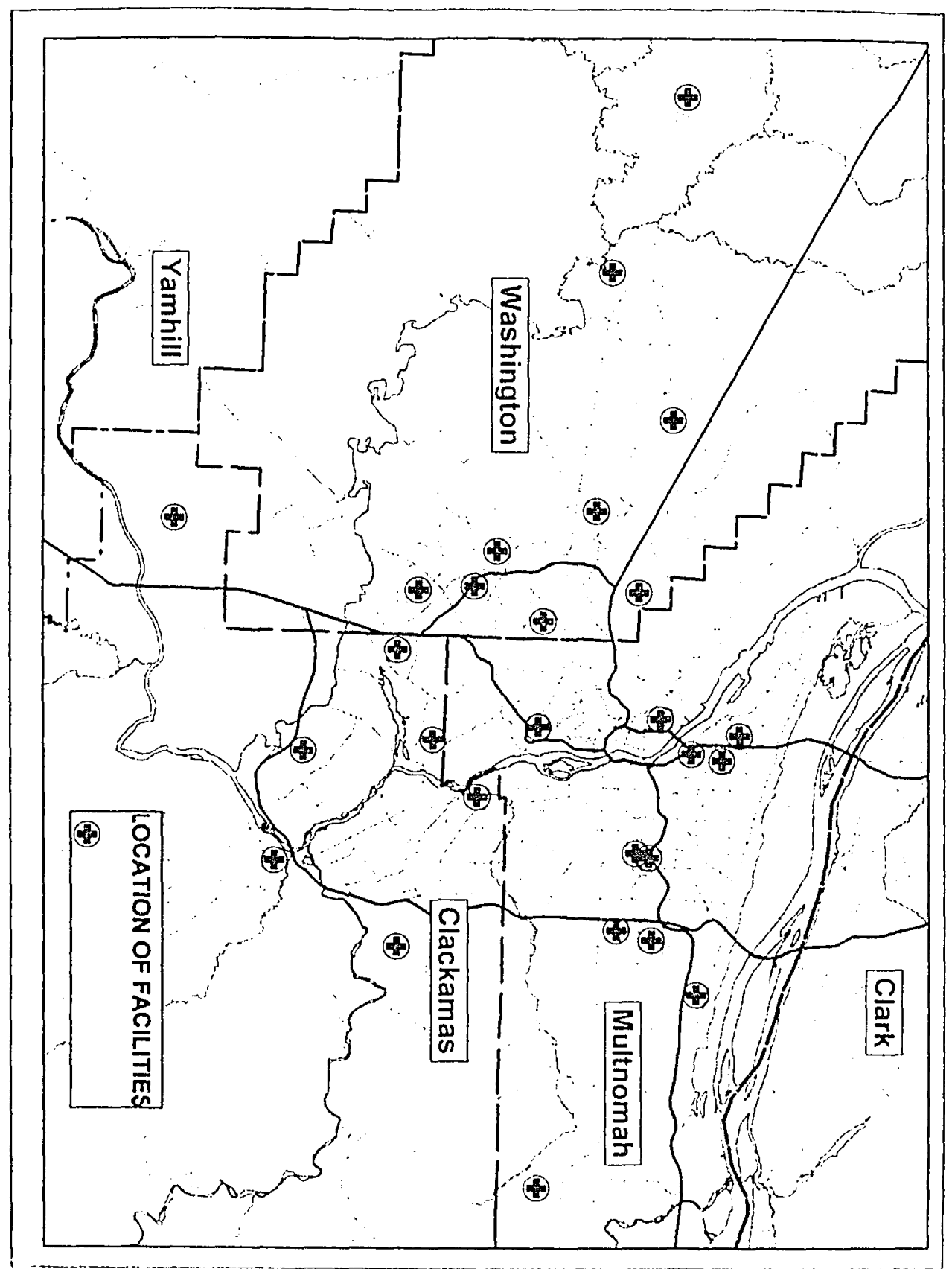

Source: Produced by an application of address matching using GIS. 


\title{
CHAPTER V
}

\begin{abstract}
ANALYSIS
The discussion of the results of the analysis of this study is presented in this chapter. The three research hypotheses are analyzed here. They are examined for the logit model of this study. This chapter is divided into three sections. The first section includes an outline of the design of the empirical analysis and the statistical techniques used to carry out the analysis in this research. The second section examines the results of the model analysis and the relationship between UCC location and the factors affecting their locations. Included also is a summary of the study model results. Finally, the third section includes a brief conclusion of the research analytical analysis.
\end{abstract}

\section{The Design of Empirical Estimation of the Model:}

The empirical analysis of the relationship between existing locations of UCC and the contributing factors assumes that UCCs are influenced by the CT within which they are located and those CTs that are adjacent. The model required the construction of an adjacency matrix, A(i,j) that have a value of 1 for adjacent CTs, otherwise 0 . Then, a population variable of each $\mathrm{CT}$ (i) was created as the product of $\mathrm{A}(\mathrm{i}, \mathrm{j})$ times Population of $\mathrm{CT}$, summed over all CTs. This measure was used 
based on prior research on service area boundary and distance decay measure of 2.5 miles radius around each UCC. This study utilizes a similar approach, which is the first tier concept, by including all the adjacent CTs to the UCC. This is a similar measure to the one stated earlier by Massey and Blake (1987). The reason for utilizing the adjacency measure was to make sure that the location of UCC is more representative of the area characteristics of the location. For instance, if the CT where a UCC is occupied by a major shopping center which is actually located in the middle area with high percentages of aged population, then the use of one CT would show that the location is only influenced by its commercial factor of location. In contrast, the adjacency measure would accurately identify any noncommercial characteristics that influence the location of a UCC.

The analysis was preceded by running some descriptive statistics to help determine what variables influence the location of UCCs. A cross-tabulation of the data was carried out by using two groups of CTs, CTs with and without UCCs versus the independent variables. Appendix B shows the descriptive statistics results. A comparison of means for the demographic and the socioeconomic variables is presented in Table III. Table III compares the means for this study's variables for both CTs with UCC present and without UCC.

The results show that the following demographic and socioeconomic variables would be useful to include in the logit models: elderly, income, whites, and females. However, the effects of one of the other variables may be masked by its association with one of the above-listed IVs. 
TABLE III

COMPARISON OF MEANS FOR THE DEMOGRAPHIC AND

SOCIOECONOMIC VARIABLES

\begin{tabular}{|c|c|c|c||}
\hline Variable & $\begin{array}{c}\text { Mean for CT } \\
\text { with UCC }\end{array}$ & $\begin{array}{c}\text { Mean for CT } \\
\text { without UCC }\end{array}$ & $\begin{array}{c}\text { Population } \\
\text { Mean }\end{array}$ \\
\hline Whites & 3920 & 3897 & 3900 \\
Elderly & 606 & 511 & 523 \\
Children & 1012 & 1140 & 1125 \\
Females & 2245 & 2196 & 2202 \\
Income & 765 & 733 & 737 \\
\hline
\end{tabular}

The independent effects of each variable can be detected by carrying out the logit model. Therefore, all the IVs will be included in both the logit and the DA models of this study.

Unit of Analysis (UOA): This study uses the CTs' areas in Portland's tricounties as the unit of analysis. As stated earlier, these CTs amount to 275. CTs were chosen because they provide a more disaggregate level of analysis due to their smaller size compared to other units of analysis such as counties or other political or administrative areas. This aspect of CTs makes them a more useful and sensitive unit for showing the effect of each independent variable.

The logit analyses should clarify the independent effect of each variable after controlling for the effects of other variables. The results from the logit estimation and the interpretation of coefficients for the dummy variables will be examined to see which variables contribute significantly to prediction of UCC locations. 
The interpretation of the results from a logit model follow that of all generalized linear models. The goal is to find the best-fitting model of the data using the fewest possible predictor variables. Parallel to the $F$ test in the regression model, the logit model most commonly uses the log-likelihood ratio statistic $\left(\mathrm{L}^{2}\right)$ as a measure of model fit. The sampling distribution of $\mathrm{L}^{2}$ approximately follows the chi-square distribution (Agresti, 1990; De Maris, 1992; Liao, 1994). The overall fit of a logit or logistic regression model is tested by comparing the likelihood ratio statistic $\mathrm{L}^{2}(\mathrm{I})$ for the independence model that includes only the intercept constant as a predictor with the likelihood ratio statistic $L^{2}(M)$ for the logit model that includes all the independent variables and the intercept. The difference $\mathrm{L}^{2}(\mathrm{I})$ L2(M) itself follows the chi-square distribution (Agresti, 1990). Thus, a logit model fits the data significantly better than the independence model when $L^{2}(I)$ $\mathrm{L}^{2}(\mathrm{M})$ is large and the associated $\mathrm{p}$-value calculated from the appropriate chi-square distribution is less than a prechosen critical value (e.g., $\mathrm{p}<0.05$; see Liao, 1994; Norusis, 1993a).

Once the effective fit of the overall logit model has been established, the contribution of specific variables to the prediction of the response variable can be analyzed (Liao, 1994, p. 13). The most straightforward way of summarizing the importance of the independent variables is to interpret $\mathrm{B}$, the logistic regression coefficient, along with $\exp (\mathrm{B})$. The logistic regression coefficient $\mathrm{B}$ is analogous to the regression coefficient $b$ in linear multiple regression. When $B$ for a given independent variable is large relative to its standard error (conventionally, B $>1.96$ 
$\mathrm{SE}, \mathrm{p}<0.05)$, the variable contributes significantly to the prediction of the outcome on the response variable (Agresti, 1990). The direction and magnitude of the effect of the independent variable is summarized by $\exp (\mathrm{B})$. When a given independent variable changes by one unit, the odds that a predicted response will occur are increased by a factor of exp (B) (Norusis, 1993a; Liao, 1994; Hardy, 1993). For instance, if the Volume of Traffic variable in the present study had an exp $(B)=$ 1.5 , this would indicate that the odds of a UCC being located in a given census tract increased 1.5 times as the score on the volume of traffic variable changed from 0 (low) to 1 (high). The examination of $\exp (\mathrm{B})$ scores for each of the independent variables thus provides a straightforward method for determining which variables are the most effective predictors of UCC location.

\section{$\underline{\text { Results }}$}

The data analysis presented a variety of outcomes. Not only do these outcomes show which factors account for UCC location, but they also show the relative independent contribution of each factor as compared to other factors.

The data analysis in this model produced results which may vary in their importance to the research hypothesis. However, the emphasis is on identifying the factors which significantly affect providers in locating existing UCCs.

\section{Results of the Logit Model}

The results of this study's model are presented in Table IV. Detailed analyses are presented in Appendix $\mathrm{C}(1)$ and Tables $1 \mathrm{C}$ and $2 \mathrm{C}$. The logit model predicted 
the location of UCCs significantly better than did the independence model that included no independent variables, $\mathrm{L}^{2}=111.26 \mathrm{df}=10, \mathrm{p}<0.001$. The effectiveness of the model was due primarily to two variables: economies of scale and volume of traffic.

TABLE IV

RESULTS OF THE LOGIT MODEL

\begin{tabular}{||l|c|c||}
\hline Variable & \multicolumn{1}{|l||}{ B } & $\exp (\mathrm{B})$ \\
\hline Whites & 0.0002 & 1.00 \\
Females & -0.0007 & 0.99 \\
Elderly & -0.0006 & 1.00 \\
Children & 0.0002 & 1.00 \\
Income & -0.0001 & 1.00 \\
Hospital & 0.3500 & 1.42 \\
Growth & 0.0005 & 1.00 \\
Volume of Traffic & $1.0600^{*}$ & 2.89 \\
Competition & 12.7700 & 350.00 \\
Commercial/office & -6.9900 & 1.00 \\
Economies of Scale & $2.1700^{* *}$ & 8.77 \\
& & \\
\hline
\end{tabular}

Note: Overall goodness of fit test for the adjacency model, $L^{2}=111.26$ $\mathrm{df}=11, \mathrm{p}<0.001$.

* $\quad$ Statistically significant at $\mathrm{p}<0.10$.

** Statistically significant at $\mathrm{p}<0.01$.

As the $\exp (B)$ scores indicate, the odds of a UCC being located in a given census tract increased dramatically as (a) economies of scale increased from low to 
high (exp $(B)=8.77)$, and (b) volume of traffic increased from low to high (exp $(B)=2.89$ ).

The results of the analysis confirm the strength of the relationship between the location of UCC and the land use factors, mainly economies of scale and volume of traffic. On the extreme, the model shows that demographic and socioeconomic factors seem to be of less importance than land use factors for providers of UCCs to locate.

Further, this study conducted some sensitivity analysis for all the demographic and the socioeconomic variables in order to test whether giving more weight to those variables over the land use variables will show any significant prediction. Several runs of the model were made with varying weights, but no significant results were found.

Table V shows the results of the model by substituting the adjacency of the population size of each CT for all the demographic variables. This run was made in order to find out whether population size is a better predictor of UCC location. The results show that population size is not significant. (Detailed analyses are presented in Appendix C(2) Table 3C and 4C).

In summary, the results of the model show that only economies of scale and volume of traffic variables are common predictors of UCC location. These results confirm that some land use factors are the best predictors of UCC location. Hence, the results support only the third hypothesis of this study which suggests that land use factors influence UCC location. On the other hand, the results did not support 
the other two hypotheses concerning demographic and socioeconomic factors' influence on UCC location.

TABLE V

RESULTS OF THE LOGIT MODEL USING THE POPULATION SIZE

\begin{tabular}{||l|c|c||}
\hline Variable & $\mathrm{B}$ & $\exp (\mathrm{B})$ \\
\hline Hospital & 0.470 & 1.60 \\
Growth & $\mathbf{0 . 0 0 2}$ & 1.00 \\
Volume of Traffic & $0.850^{*}$ & 2.33 \\
Competition & 11.850 & 140.00 \\
Commercial/office & 1.190 & 1.00 \\
Economies of Scale & $2.120^{* *}$ & $\mathbf{8 . 4 0}$ \\
Population (adj) & 1.320 & 1.00 \\
& & \\
\hline
\end{tabular}

Note: Overall goodness of fit test for the adjacency model, $\mathrm{L}^{2}=114.73 \mathrm{df}=7$, $\mathrm{p}<0.001$.

* Statistically significant at $\mathrm{p}<0.10$.

** Statistically significant at $\mathrm{p}<0.01$.

Although the intent of the utilization of sensitivity analysis was to detect any measurable influence of the demographic and socioeconomic factors by utilizing adjacency matrix, the findings were not significant.

The results of the model for predicting UCC location confirm the third hypothesis of this study. With respect to the strength and direction of the ruationship between UCC location and to land use factors, the model constructed 
affirms the existence of a strong relationship between UCC location and the above factors. The model shows that, controlling for other variables, some land use factors are strong predictors of UCC location. The model confirms that UCCs will located close to major group practitioners, medical facilities, and high traffic volume areas.

Another conclusion is that other demographic factors such as percentage of and number of children and females are weak determinants of UCC location. Consequently, these factors are not considered fully by providers of UCCs.

Economies of scale variables continue to be the most common strong predictors of UCC location, followed by volume of traffic. Contrary to the first and second hypotheses and prior research, demographic and socioeconomic factors seem to show very weak predictability of UCC location. This finding confirms the fact that, although health care literature, economic theories, and market segmentation approaches suggest that providers should locate UCCs close to their major users, providers of UCCs in the Portland metropolitan area do not respond to their major users. This finding assumes that the location pattern of UCCs is not related to the demographic or socioeconomic character of the population. One interpretation of this study's finding is that providers of UCCs select the location of UCCs based on areas where successful practitioner groups are located. So, in essence, practitioner groups locate first, then UCCs follow them. This suggests that providers of UCCs value economies of scale factors more than they do their major users.

The model produced a variety of predictions for UCC location in relation to 
land use. Table IV shows the importance of the relationship between UCC location and the above factors. A strong relationship exists between UCC location and land use variables, múnly economies of scale and volume of traffic factors. This relationship is much stronger in predicting the location of UCCs than are other demographic and socioeconomic factors.

\section{Conclusions}

Basically, the results of the logit model, presented in Appendix C, Table 1C, show that 241 CTs were predicted correctly not to have UCCs, while 32 CTs were predicted incorrectly to have UCCs. So, the only reason we have any sort of predictability out of this model is because of the CTs that do not have UCCs. Therefore, the model actually predicts where UCCs are not to be located, but does not predict well where they do locate. The reason that economies of scale and volume of traffic were chosen by the model as important predictors is because these variables are considered rare phenomena. Thus, economies of scale and volume of traffic are the only two variables that should be carried out for future research to be investigated further in relation to UCC location. However, demographic factors may still have an indirect influence on UCC locations. These indirect effects stem from the fact that there is an indirect relationship between demographic variables and economies of scale. Since this study shows that economies of scale are important predictors of UCC location, this might imply that providers of UCCs apply some screening process to the location where group practitioners select their 
locations in order to be close to their populations. If group practitioners locate in relation to their populations, that could be used as an indirect measure by providers of UCCs to determine their locations. 


\section{CHAPTER VI}

\section{RESEARCH FINDINGS}

The analysis of this study has examined UCC location and the factors that affect their location in the Portland, Oregon metropolitan area. The results of the analysis, discussed in the previous chapter, has shown which factors are important predictors of UCC location. This chapter discusses the major research findings. It describes the results of the model and the contribution of each factor on UCC location. A conclusion of the major findings of the research are summarized at the end of this chapter.

\section{LAND USE FACTORS' INFLUENCE ON UCC LOCATION}

The empirical findings of this research substantiate the existence of a strong relationship between the location of UCCs and land use factors. The statistical analysis supports the notion that land use factors are important determinants of UCC location. Land use variables predict where UCCs do not locate, but do not predict well where they do locate. However, given that UCC location is a rare phenomenon, some speculation still arises concerning the influence of these variables. 
Nevertheless, the magnitude of the relationship varies across the variables. The significance and contribution of each factor (presented in Chapter V) shows variable effects of land use factors on the location of UCCs. Two variables are important here: economies of scale and volume of traffic are the strongest predictors among land use factors on UCC location. First, with respect to UCC location, the economies of scale variable have significantly high log-likelihood. This means that providers of UCCs tend to take advantage of being located close to practitioners' offices and other medical facilities. Further, volume of traffic comes next as a good predictor of UCC location. Similarly, providers of UCC give more attention to $\mathrm{CT}$ or locations which are more accessible to major highways. Taken altogether, land use variables account for the highest probability in predicting UCC location. These findings reject the fact suggested by most prior health care research (see Chapter II, Literature Review), which never considered land use factors as important determinants of UCC location.

Second, with respect to their effect on UCC location, demographic and socioeconomic factors are weak likelihood predictors for UCC location. This means that providers of UCCs give demographic and socioeconomic factors less consideration than land use variables in selecting the location of UCCs. Contrary to the well-acknowledged notion that demographic factors may have strongly influenced providers' decisions to locate UCCs, this study shows that their influence is not as strong as acknowledged.

What the models in this study show is that a sizable consideration of land use 
factors are given by providers' decisions to locate UCCs. This strong influence of land use factors is attributed to several important issues. First, economies of scale factors encourage providers to take advantage of nearby major practitioners' groups and medical facilities. These advantages include the use of medical emergency equipment that is not available in the UCC, or to utilize nearby medical group physicians in case of the absence of the UCC resident physician. Second, areas with high volumes of traffic around the location of the UCC make it more convenient and accessible to be seen and to be used by more people.

\section{Land Use Factors}

Land use factors are some of the most important determinants of UCC location. Economies of scale and volume of traffic seem to influence the UCC decision makers to concentrate their locations in these areas. This may lead to uneven distributions of UCCs in urban areas. In fact, the clustering of UCCs in certain areas causes some areas to be over-supplied while other areas are under-supplied.

At the CT level, those with proximity to major practitioner groups and medical facilities have the highest probability of being selectd as locations for UCCs. On the other hand, CTs with no practitioner offices or medical facilities have a lower probability of being chosen for UCC locations. In these areas, residents need to travel farther to get urgent care than do residents in areas where economies of scale are present.

Similarly, but to a lesser degree, areas with high volumes of traffic are targeted 
by providers of UCCs, and this explains in part why these UCCs are located close to major highway intersections.

Despite expectations that high percentages of commercial and office space in the CT will produce a higher probability for UCCs to locate in that CT, these factors did not influence the location patterns of UCCs. This finding rejects the notion that existing UCCs in the Portland metropolitan area are located close to major shopping centers and concentrations of office buildings. In fact, more UCCs are located away from commercial areas.

\section{Demographic and Socioeconomic Factors}

Demographic and socioeconomic factors were not good predictors of UCC location. Numbers of whites, children, females and elderly were not found to be important predictors of UCC location. This research uses income as an indicator of most socioeconomic factors. Income was proved to be of less importance to providers of UCC location. In contrast with prior research, which suggests that UCCs and other HCFs usually target high income areas, this research show the contrary effect. This finding is based on the analysis of existing locations of UCCs in the Portland metropolitan area. However, this failure to find any relation between existing UCC locations and the above factors may be due to the fact that in 1990 existing providers of UCCs in Portland were not aware of the advantages of proximity to wealthy neighborhoods. However, demographic factors may still have an indirect influence on UCC locations. These indirect effects stem from the fact 
that there is an indirect relationship between demographic variables and economies of scale. Since this study shows that economies of scale are important predictors of where UCCs will not be located, this might imply that group practitioners select their locations to be close to their populations. If group practitioners locate in relation to their populations, that could be used as an indirect measure by providers of UCCs to determine location.

\section{Other Factors Influencing UCC Location}

Due to the fact that the variables in this study do not explain all the changes in UCC location, this study suggests that it would be more appropriate to research and utilize more as yet undiscovered variables that might have major effects on UCC location. For instance, this study included two important, though overlooked, variables which are economies of scale and volume of traffic. These two variables have proved to have more influence on UCC location than other variables suggested by health care literature. This finding shows the complexity of determining all the variables affecting UCC location. Nevertheless, some of the unexplained variation on UCC location may be attributed to some unknown or not-yet-researched variables such as some interorganizational factors. Some of these factors are intangible while some may still be quantifiable. More research is needed to identify these variables and to incorporate them in future similar studies.

\section{Conclusions}

The primary objective of this study has been to analyze the factors affecting 
the location of UCCs in urban areas. For this objective, the case study of Portland, Oregon was conducted to study and analyze such effects. The research question was aimed at determining which of the land use, demographic, and socioeconomic factors account for the location of existing UCCs. In addition to its utilization of variables suggested by prior research, this study is unique in terms of both its inclusion of new variables which were important determinants of other facilities' locations, and in using adjacency measurements of the DV. No previous work has attempted to do this.

This study systematically investigates the influence of demographic, socioeconomic, and land use variables on UCC location in the Portland metropolitan area and, yet, fails to uncover the important variables underlying UCC location. This finding postulates that if previous literature on the relationship between UCCs' locations and the above variables is not based on empirical analysis, and this study could not prove any such relationship, then this raises some speculation about how previous literature reached such conclusions.

Second, the difficulty faced by this study to uncover the relationship between UCCs and the above variables may be due to the fact that the Portland metropolitan area is unique in the presence of a high proportion of HMO populations. In this case, it is unique in that people travel to reach urgent care according to their affiliated UCCs, regardless of their location. These results might differ in other cities where there are lower proportions of HMO populations. Therefore, the findings of this study cannot be replicated in or generalized to other urban areas. 
In fact, this study proves very clearly that the bulk of the literature cannot be substantiated based on existing publicly available data, and, unless health care providers are willing to release their client data, they cannot continue to rely on theories that exist in the literature. It is rather interesting that the data available does not provide enough evidence to substantiate what is mentioned in the literature. It does not mean that what the literature suggests is wrong but that it is based on the available data which really cannot support such conclusions. 


\section{CHAPTER VII}

\section{DISCUSSION AND RESEARCH IMPLICATIONS}

This case study of UCC location in Portland, Oregon, in relation to demographic, socioeconomic and land use factors, aids our understanding of the phenomenon of UCC growth in urban areas. Existing research has acknowledged the influence of these factors for most HCFs but has never systematically examined these relationships for UCCs. The findings of this study and of similar future research in this field will help to fill this gap.

The study approaches and analysis have also provided new direction for future research in spatial analysis of UCC location. This study highlights the complexity and importance of understanding the factors influencing the location of UCCs. This research denies some prior arguments that UCC location is influenced by some demographic, socioeconomic and land use factors in the Portland metropolitan area.

This chapter discusses the limitation of this study, and describes some of the relevant planning and policy implications of the research findings. It ends with suggestions for further research.

\section{$\underline{\text { Research Limitations }}$}

The study was intended to provide a basic research foundation for future 
research in this new and overlooked UCC location problem. Given that there had been little prior research in this regard, this study was based largely on comparisons of prior research on other HCFs. To study the relationship between existing UCC locations and the factors influencing their location, the study relied on quantitative analysis and suggests the incorporation of new factors which were overlooked by prior research on HCFs. Most of the land use factors introduced in this study were suggested based on comparison of factors influencing other urban facilities. The findings of this study which show that land use factors are of significant importance for UCC location still need to be tested for other urban areas.

The study did not include some other factors related to the consumer side such as variation in lifestyles and behavioral factors. These factors may contribute to the findings of this study; however, they cannot be accounted for using quantitative analysis. More advanced qualitative analysis is needed for future research.

One of the obstacles of this research is data availability for UCCs. The study relied on publicly available data which have been gathered from different public and private agencies and through published reports. Therefore, the accuracy of data in this study can be a concern. They have limited most of the study models and did not allow for more flexibility in including other relevant variables.

In terms of empirical analysis, most statistical techniques, including logit analysis, cannot isolate causes from effects. Prior researchers have pointed out the difficulty of isolating cause from effect in the study of locational analysis. Similarly, the influence of the factors presented in this study on UCC location may 
require in depth analysis of change over time. Cross-sectional analyses do not show the real variation in time-scale since they represent only a one-shot examination of existing conditions. Further research and data availability could overcome these limitations.

The findings of this study are based solely on extra-organizational factors which do not give a clear view of the larger picture of the complexity involved in examining the factors affecting UCC location. This study warrants the need for more rigorous statistical analysis and techniques to bring together all the factors influencing UCC location. The findings of this study are based only on the provider side. Therefore, some of the unexplained variance may be attributed to intra-organization factors.

Finally, as stated previously, the results of this case study cannot be generalized to other urban areas unless more research is generated and representative samples of urban areas are examined. Data availability for other urban areas is still a concern for future research in this context.

\section{Planning and Policy Implications}

The findings of this study have significant planning and policy implications. Health care officials, regulators, policy makers and marketing experts are increasingly aware of the importance of understanding the influence of each demographic, socioeconomic and land use factor on HCF location. However, little attention is paid toward the study of UCC location. Concerns about the even 
distribution of UCCs in relation to major users in the city are somehow neglected. Demographic influence on UCC location is not reasonably considered by providers of UCCs. As explained earlier, the elderly population is growing in number. They are the largest consumers of health care, and the basic group for market segmentation (see Chapter II). Therefore, planners and health care officials should be more responsive to current and future demographic changes in locating UCCs. Further, females are more frequent users of UCC than are males. The changing role of women in American society and their enrollment in the work force alleges the need to improve their accessibility to UCCs.

In addition, other factors contributing to UCC location are also important for health care regulators and policy makers. In Portland, as in other cities in the U.S., there is little regulation of UCC location. Therefore, more regulating policies are needed to grant more effective distribution of urgent care to all members of the community. Policy makers and health care regulators could have an impact on these policies and, in turn, affect urban growth and development of urgent care facilities. As we see a growing penetration of managed care in the Portland metropolitan area, we might expect, in the near future, the revival of health care planning which virtually disappeared in the early 1980 s.

Further, the Oregon Health Plan (OHP) and managed health care organizations in Portland are contracting amongst the UCCs. Therefore, future UCC location decisions may have a lot more to do with relationships driven by where their populations are and by the primary locations of those OHP or HMO populations. 
This study had some difficulty while conducting the survey for UCCs in Portland, stemming from the fact that there is no clear definition of an "urgent care center," and that there is much confusion between what are UCCs and emergency centers (ERs). ERs are complex organizations, and most health care literature fails to distinguish them from UCCs. Researchers have to be able to distinguish between these two different kinds of facilities. Otherwise, this confusion may invalidate the findings of their research. The failure to distinguish between these facilities reflects that the organizations that deliver health care are changing very rapidly while health care research is not responding to study this confusion.

UCCs seem to be off the agenda of most researchers and health care marketing experts in the U.S. and in Portland. During this study, little information or secondary data were found in any of the major health care agencies. It is a wellknown fact, that the availability of data bases is the most important step toward effective planning. Updating and integrating these data into some data base program and linking them to today's more sophisticated geographic information systems are a must for effective future planning. Updating the data bases can help in understanding future changes.

The findings of this study show that some demographic segments of the population are not given a great deal of consideration by providers of UCCs. For instance, the elderly, according to the literature, are the greatest consumers of health care in general; thus, their accessibility to urgent care is warranted. More policies and regulation are needed to control the development of UCC locations in relation 
to major users of urgent care.

This study suggests a needed combined effort from both the public and the private sectors of health care as well as some input from state officials to control the growth of UCCs in urban areas. But, relying on the private sector or the market to mitigate the negative externalities of this uneven distribution of UCCs may be too risky. Without official intervention and health care regulation, the accessibility of urgent care is not optimal to the population needs. Most of the recommendations of this study require strong local government intervention to achieve better coordination and integration of UCC locations in relation to the existing inventory of health care facilities in the city.

Although the findings of this study are based entirely on empirical evidence, it may be assumed that further studies will be needed to achieve better results. It must be emphasized that this study's analysis represents only a first approximation of the problem which has several unexplored dimensions. As additional research progresses in this direction, a more complete examination of this locational problem should be observed.

\section{Suggestions for Further Research}

This study of factors underlying UCC location in Portland, Oregon, is of interest to health care officials and planners. The findings of this study contribute to the basic ground work for future research in UCC location by identifying the influence of each demographic, socioeconomic, and land use factor on UCC location. 
One of the basic suggestions for future research found by this study is to devote some effort to collecting as much reliable and updated data as possible for future work. This can be achieved through surveys as well as other data collection methods.

More support from local governments is needed to sponsor research work on UCCs not only on the locational aspects but also as a phenomenon which is rapidly growing in most cities in the U.S.

Geographic Information Systems (GIS) provide the opportunity for such analysis to be used in conjunction with some spatial analysis models such as gravity, location allocation, and other optimal location models and integrated with GIS to provide some optimal location patterns and to enhance accessibility to UCCs in urban areas.

This study indicates that it is incumbent upon UCC providers and those who have access to client data to release the needed data and to carry out some spatial choice modeling to determine the appropriate extent of distance decay of service areas for UCCs. Such research will help future researchers extend the approach of this study, which was based on adjacent CTs, to determine whether adjacent zones were sufficient to carry out such a locational analysis.

Moreover, this study calls for more research and refinement of economy of scale factors as presented in this study. Group practitioners were the main variable for measuring economies of scale in this study. More research is needed to include other organizational-specific economies of scale and to measure such factors. Further, based on this study, more research is needed to examine the relationships 
between the location of the non-UCC group practitioners and UCC locations, as they appear to be complementary facilities.

This study suggests devoting more effort toward bridging the gap between land use theories of location and health care research and marketing. Most health care research focuses on competition, and on economic and organizational strategies of health care facilities, in isolation from some well-known and useful theories of land use and facility location. It is understandable that health care facilities are different from most urban facilities. However, UCCs are shown in the literature review of this study to be business-oriented facilities. This recent change to UCCs alleges a need for health care research to borrow some approaches from location theories. Recent transitions in the health care industry should be accompanied by a change in the way medical research is carried out in the free market.

Finally, this study suggests that it is incumbent upon health care providers to release their client data in order to gain better research. In fact, the literature on which health care providers rely on cannot be supported by existing research unless they are willing to release their client data so that better research is conducted. 


\section{REFERENCES}

Agresti, A. (1990). Categorical Data Analysis. New York, John Wiley \& Sons.

Aldrich, J. H. and Nelson, F. D. (1984). Linear Probability, Logit, and Probit Models. Beverly Hills, CA: Sage.

Alonso, W. (1965). Location and Land Use. Cambridge, Mass.: Harvard University Press.

Babbie, E. (1983). The Practice of Social Research. Belmont: Wadsworth.

Basu, Ramala. (1982). Use of Emergency Room Facilities in Rural Areas: A Spatial Analysis. Social Science and Medicine, Vol. $16: 75-84$.

Bay, K. S. and Nestman, L. J. (1980). A Hospital Service Population Model and its Application. International Journal of Health Services, Vol. 10, No. 4. Baywood Publishing Co., Inc.

Beckham, J. D. (1984). A Strategic Alternative for Community Hospitals: The Principle of Peripheral Penetration. Journal of Health Care Management, 4 (Winter): $37-40$.

Beck, D. F. and Dempsey, J. (1990). Health Care Cost: The Other Point of View. Health Service Research, 9 (2), December, 1-11.

Berry, B. J. (1967). Geography of Market Centers and Retail Distribution. Englewood Cliffs, N. J.: Prentice-Hall.

Ben-Akiva, Moshe, and Lerman, Steven R. (1985). Discrete Choice Analysis: Theory and Application to Travel Demand. The MIT Press, Cambridge, Massachusetts.

Bowers, Michael. R., Swan, John. E. and Taylor, Jack. A. (1994). Influencing Physician Referrals. Journal of Health Care Marketing, Vol. 14, No. 3, Fall, 42-50.

Bridgman, R. R. (1979). Hospital Utilization: An International Study. Oxford University Press. London.

Browning, S. M. (1993). Forces for Reforming the U.S. Health Care System: A Review of the Cost and Access Issues, from North American Health Care Policy in the 1990s. A. King et al., New York, John Wiley \& Sons Ltd. 
Burns, L. A. (1991). Financial Issues in Ambulatory Care. Top Health Care Finance, 17 (3): $53-65$.

Cashman, S. B., et al. (1991). The Patient Population of a Major Chain of Investorowned Ambulatory Care Walk-in Centers. Journal of Ambulatory Care Management. 14(1): 66-77. Aspen Publishers, Inc.

Cashman, S. B., et al. (1991). Investor-owned Ambulatory Care Walk-in Centers: How Have Primary Care Physicians Responded. Journal of Ambulatory Care Marketing, Vol.

II, No. 3, September: 61-68.

CPRC; Center for Population Research and Census; Published Reports (1994). Portland State University. Portland, Oregon.

Chatfield, C. and Collins, A. J. (1980). Introduction to Multivariate Analysis. New York: Chapman and Hall.

Chulis et al. (1993). Health Insurance and the Elderly. Health Care Finance Review, Vol. 14, No. 3, Spring.

Ciocco, A. and Altenderfer, R. (1945). Birth Statistics as an Index of Interdependence of Counties with Regard to Medical Services. Public Health Reports, No. 60 (34).

Clark, C. and Krentz, S. E. (1991). Planning Long-term Care Services: A Guide for Acute Care Hospitals, 17(40): 73-82. Aspen Publishers, Inc.

Clark, W. A. V. and Hosking, P. L. (1986). Statistical Methods for Geographers. New York, John Wiley \& Sons.

Cokelez, S. and Peacock, E. (1993). A Modeling Approach to Spatial Location for Effective Marketing. Journal of Health Care Marketing, Vol. 8 (1).

Cramer, J. S. (1991). The Logit Model : An Introduction for Economists. Routledge, Chapman and Hall Inc. New York, NY.

Cromley, E. K. and Albertson, P. C. (1993). Multiple-site Physician Practices and Their Effect on Service Distribution. Health Service Research, 28:4, October, 503-520.

Cromley, E. K. and Shannon, G. W. (1986). Locating Ambulatory Medical Care Facilities for the Elderly. Health Service Research, 21:4, October. 
Dant, Rajiv P., Lumpkin, J. R., and Bush, Robert P. (1990). Private Physician or Walk-in Clinics: Do the Patients Differ? Journal of health Care Marketing, Vol. 10, No 2, pp. 23-35.

Day, R. A. (1973). Consumer Shopping Behavior in a Planned Urban Environment. Tijdschrift voor Econ. en Soc. Geografie, Vol.64, No. 2.

Dennision, Robert, Kathawala, Yunus, and Elmuti, Dean. (1993). Just-In-Time: Implications for the Hospital Industry. Journal of Hospital Marketing. Vol. 8(1). 131: 162.

Dolinsky, A. and Caputo, R. K. (1990). The Role of Health Care Attributes and Demographic Characteristics in the Determination of Health Care Satisfaction. Journal of Health Care Marketing, Vol. 10, No. 4, December: 31-39.

d'Amico, M. F., Hawes, J. M. and Lewison, D. M. (1994). Determining a Hospital's Trading Area: An Application of Reilly's Law. Journal of Health Care Marketing, Vol. 8(2): 121.

Dunteman, G. H. (1984). Introduction to Multivariate Analysis. Beverly Hills: Sage Publications.

Flexner, W. A. and Berkowitz, E. N. (1979). Marketing Research in Health Services Planning: A Model. Public Health Reports, Vol. 94, No. 6, NovemberDecember, 503-514.

Fraser, I. et al. (1993). Ambulatory Care: A Decade of Change in Health Care Delivery. Journal of Ambulatory Care Management, Vol. 16(4): 1-8.

Gesler, W. M. and Meade, M. S. (1988). Locational and Population Factors in Health Care-Seeking Behavior in Savannah, Georgia. Health Service Research, 23:3, August, p. 42-62.

Ghosh, V. and McLafferty, S. L. (1987). Location Strategies for Retail and Service Firms. Lexington Books.

Ghosh, V. and Rushton, G., (1987). Spatial Analysis and Location-Allocation Models. New York: Van Nostrand Reinhold Company.

Goodchild, M. F. and Noronha, V. T. (1983). Location-Allocation for SmallComputers. Monograph No. 8. Iowa City: Department of Geography, University of Iowa.

Greenhut, M. L. and Ohta, H. (1975). Theory of Spatial Pricing and Market Areas. 
Raleigh, North Carolina: Duke University.

Gruca, T. S. and D. Nath (1994). The Impact of Marketing on Hospital Performance. Journal of Hospital Marketing, Vol. 8(2): 87-112. The Haworth Press, Inc.

Hardon, D. (1991). The Role of Public Values in Setting Health Care Priorities. Social Science Medicine, Vol. 32, No. 7: 773-781.

Hardy, Melissa A. (1993). Regression With Dummy Variables. Quantitative Applications in the Social Sciences. Beverly Hills, Sage Publications Inc.

Harrell, G. D. and M. F. Fors (1985). Marketing Ambulatory Care to Women: A Segmentation Approach. Journal of Health Care Marketing, Vol. 5, No. 2, Spring, 19-28.

Hays, S. M., R. Kearns and W. Moran (1991). Spatial Patterns of Attendance at General Practitioner Services. Social Science Medicine, Vol. 31, No. 7: 773791.

Heischmidt, Kenneth, Firooz Hekmat and Peter Gordon (1993). A Multivariate Analysis of Choice Criteria for Hospitals. Journal of Health Care Marketing, Vol. 8(1): 41.

Helbing, C. C., V. B. Latta and R. E. Keene (1990). Hospital Outpatient Services Under Medicare. Health Care Financing Review, Vol. 11, No. 4: 147-152.

Oppong, J. R. and Hodgson, J. (1989). Some Efficiency and Equity Effects of Boundaries in Location-Allocation Models. Geographical Analysis, Vol. 21, No. 2, April. Ohio State University Press.

Huxhold, William, E. (1991). An Introduction to Urban Geographic Information Systems. New York, Oxford University Press.

Isard, W. (1960). Methods of Regional Analysis: An Introduction to Regional Science. Cambridge, Mass. and London, England: The M. I. T. Press.

Joseph, Alun E. and Petter R. Bantock. (1982). Measuring Potential Physical Accessibility to General Practitioners in Rural Areas: A Method and Case Study. Social Science and Medicine, Vol. $16: 85-90$.

Kassaye, W. W. and K. C. Tseng (1990). Effects of Changes in Micro- and MacroEnvironmental Factors on the Supply of Hospital Services. Journal of Hospital Marketing, Vol. 4 (1). The Haworth Press, Inc. 
King, L. J. (1984). Central Place Theory. Scientific Geography Series Vol. 1. Beverly Hills: Sage Publications Inc.

Knaap, Gerrit J, and Diane Blohowiak. (1989). Intraurban Physician Location; New Empirical Evidence. Medical Care, (December) Vol. 27, No. 12, 1109-1116.

Kotler, P. and R. Clarke (1987). Marketing for Health Care Organizations. Englewood Cliffs, NJ: Prentice-Hall, Inc.

Kovner, A. R. ed. (1990). Health Care Delivery in the United States, Ch. 6. Ambulatory Care by Stevens, Jonas and Stephen N. Rosenberg. New York, NY: Springer Publishing Company.

Lancaster, W. and R. Boissoneau (1990). Selecting a Primary Care Physician: Results of a Study. Journal of Hospital Marketing, Vol. 5 (1): 139-149.

Lewis-Beck, M. S. (1980). Applied Regression: An Introduction. Beverly Hills, Sage Publications, Inc.

Liao, Tim Futing. (1994). Interpreting Probability Models : Logit, Probit, and Other Generalized Linear Models. Sage Publications, Thousand Oaks, CA.

Lowell-Smith, E. G. (1993). Regional and Intrametropolitan Differences in the Location of Freestanding Ambulatory Surgery Centers. Professional Geographer, Vol. 45 (4): 398-407. Cambridge: Association of American Geographers, Blackwell Publishers.

Love, D. and Lindquist, P. (1995). The Geographical Accessibility of Hospitals to the Aged: A Geographic Information Systems Analysis within Illinois. Health Services Research. 29:6, February, 629-631.

Lumpkin, J. R. and Tudor, K. R. (1990). Walk-in Clinics Versus Private Practitioners: Determinant Attributes of Health Care Provider Choice Among the Elderly. Health Marketing Quarterly, Vol. 8(1/2):119. The Haworth Press, Inc.

MacDowell, N. M. and Perry, R. (1990). Factors Influencing Physician Choice of an Outpatient Surgery and Testing Facility. Health Care Marketing Minicase. Journal of Health Care Marketing, Vol. 10, No. 3, September: 67-74.

Malone, Ruth, E. (1995). Heavy Users of Emergency Services: Social Construction of a Policy Problem. Social Science and Medicine, Vol. 40, No. 4. 469:477.

Massey, T. K. and Blake, F. (1987). Estimating Market Boundaries for Health Care Facilities and Services. Journal of Health Care Marketing, Vol. 7, No. 3. 
September, 15-24.

Mayhew, L. (1986). Urban Hospital Location. London, England: George Allen \& Unwin.

McLafferty, S. (1982). Urban Structure and Geographical Access to Public Services. Annals of the Association of American Geographers, Vol. 72: 347-54.

McLafferty, S. (1982). Neighborhood Characteristics and Hospital Closures: A Comparison of the Public, Private and Voluntary Hospital Systems. Social Science Medicine, Vol. 16: 1667-1674.

McLafferty, S. (1986). The Geographical Restructuring of Urban Hospitals: Spacial Dimensions of Corporate Strategy. Social Science and Medicine, Vol. 23: 1079-1086.

Meade, J. (1974). A Mathematical Model for Deriving Hospital Service Area. International Journal of Health Services, Vol. 4, No. 2.

Mick, S. S. and Associates (1990). Innovations in Health Care Delivery: Insights for Organization Theory. San Francisco: Jossey-Bass Publishers.

Miller, M. E. and M. B. Sulvetta (1992). Medicare Hospital Outpatient Service and Costs: Implications for Prospective Payment. Health Care Financing Review, Vol. 14, No. 2, Winter.

Morrill, R. (1993). Development, Diversity, and Regional Demographic Variability in the U.S. Annals of the Association of American Geographers, 83(3): 406-433.

National Ambulatory Medical Care Survey (NAMCS) (May, 1994): 1991 Summary National Center for Health Statistics. U. S. Department of Health and Human Services.

National Ambulatory Medical Care Survey (NAMCS) (1980): National Medical Care Utilization and Expenditure Survey: Family Use of Health Care. Health Care Financing Administration. National Center for Health Statistics. U. S. Department of Health and Human Services.

National Medical Utilization and Expenditure Survey : Family Use of Health Care, U.S. (1980). Health Care Finance Administration. Office of Research and Demonstration. Department of Health and Human Services.

Nauert, R. C. (1992). Planning an Alternative Delivery System. Top Health Care Finance. 18(3): 64-71. Aspen Publishers, Inc. 
Nestor, S. E. (1992). Marketing to Consumers: Unleashing Technologies to Help the Public Choose Health Service Options. Topics in Health Care Finance, Vol. 18(3): 28-37.

Newman, R. G. (1984). A Conjoint Analysis in Outpatient Clinic Preferences. Journal of Health Care Marketing, Winter, 41-49.

Norusis, M. J. (1993a). SPSS for Windows: Advanced Statistics, Release 6.0. Chicago, IL: SPSS.

Norusis, M. J. (1993b). SPSS for Windows: Professional Statistics, Release 6.0. Chicago, IL: SPSS.

Oregon Hospital Statistics (OHS) 1987-1991, (1991). Department of Human Resources, Salem, Or.

Oppenheim, N. (1980). Applied Models in Urban and Regional Analysis. Ch. 4: 157163. Englewood Cliffs, NJ: Prentice-Hall, Inc.

Ortinau, D. J. (1986). Discriminating Users and Nonusers of Preventive Health Care Practices and Emergency Medical Walk-in Clinics. Journal of Health Care Marketing, Vol. 6, No. 2, June, 26-35.

Plane, D. A. and Rogerson, P. A. (1991). Tracking the Baby Boom, The Baby Boom Bust, and the Echo Generations: How Age Composition Regulates U.S. Migration. Professional Geographer, 43(4): 416-430. Association of American Geographers.

Petrie, J. T. (1992). Medicare Supplementary Medical Insurance Benefit for Hospital Outpatient Services. Health Care Finance Review/Annual Supplement: 183199.

Philibert, L., Thouez, J. P. and Beland, F. (1992). The Use of Hospital Emergency Services in the Quebec Metropolitan Region. The Canadian Geographer, Vol. 36, No. 1: 45-65.

Phillips, Charles. R., Schuler, Drue K. and Jacobs, Elgene W. (1994). Inequality in Health Insurance Reform: Are the Elderly More at Risk? Journal of Health Care Marketing. Vol. 14, No. 4, Winter, 14-22.

Phillips, J. H. and Reeder, C. E. (1987). Ambulatory Care Centers: Structure, Service and Marketing Techniques. Journal of Health Care Marketing, Vol. 7, No. 4, December, 27-32. 
Plested, W. G., M.D. (1991). Ambulatory Care-1990: A View from the Trenches. Journal of Ambulatory Care Management, 14 (4) October, 40-47. Aspen Publishers, Inc.

Reinke, W. A., editor. (1988). Health Planning for Effective Management Ch. 3. New York: Oxford University Press.

Reisman, David. (1993). The Political Economy of Health Care. St. Martin Press, New York, NY.

Rocco, K. (1993). A Review of State Health Care Program Costs. (Prepared by Kenneth Rocco, D. Wilson, and A. Wilkinson of the Legislative Fiscal Office) Salem, OR.

Ross, A., Williams, S. J. and Schafer, E. L. (1984). Ambulatory Care Organization and Management. New York: John Wiley \& Sons, Inc.

Rushton, G. (1979). Optimal Location of Facilities. Wentworth, NY: COMPress, Inc.

Rushton, G., Goodchild, M. F. and Ostresh, L. M. Jr. (1973). Computer Programs for Location-allocation Problems. Monograph No. 6. Iowa City: Department of Geography, University of Iowa.

Salmon, J. Warren. (1995). A Perspective on the Corporate Transformation of Health Care. International Journal of Health Services, Vol. 25, No. 1. 11:42.

Schramm, C. J., (1987). Health Care and Its Costs. New York: W. W. Norton.

Schul, Patrick L., Remington, Steven J., and Planchon, John M. (1994). The Strategic Marketing Reaction of Conventional Nonprofit Hospitals to the Market Entry of Alternative Care Provider Organizations. Journal of Health Care Marketing, Vol. 8 (2). 131:145.

Shannon, G. W. and Dever, G. E. A., (1974). Health Care Delivery: Spatial Perspectives. New York: McGraw-Hill Book Company.

Shortell, S. M., Morrison, E. M. and Friedman, B. (1990). Strategic Choices for America's Hospitals: Managing Change in Turbulent Times. San Francisco: Jossey-Bass Publishers.

Sirkin, Mark R. (1995). Statistics for Social Sciences. Thousand Oaks, CA: Sage Publications Inc.

Spiegel, A. D., and Hyman, H. H. (1978). Basic Planning Methods. Aspen Systems 
Corporation. Germantown: MD.

Spotts, H. E. andSchewe, C. D. (1989). Communicating with the Elderly Consumers: The Growing Health Care Challenge. Journal of Health Care Marketing, Vol. 9, No. 3, September, 36-44.

Stevens, James. (1992). Applied Multivariate Statistics for Social Sciences (2nd ed). Hillsdale, N.J. : L. Erlbaum Associates.

Sykes, C. S. (1991). The Role of Equity Financing in Today's Health Care Environment. Top Health Care Finance, 18(1): 1-4. Aspen Publishers, Inc.

Tabachnick, B. G. and Fidell, L. S. (1983). Using Multivariate Statistics. New York: Harper and Row.

Thorpe, K. E. and Brecher, C. (1989). Comparative Analysis of Efficiency and Access From Altman et al., 1989. Competition and Compassion. Ann Arbor, Health Administrative Press.

Tkocz, Zygmunt, and Kristensen, Gustav. (1994). Commuting Distances and Gender: A Spatial Urban Model. Geographical Analysis, Vol. 26, No. 1 (January).

Toso, M. E. and Farmer, E. (1994). Using Cost Accounting Data to Develop Capitation Rates. Topics in Health Care Financing, Fall. Vol. 21(1): 1-12.

Wagner, H. C. et al., (1994). Relationship Marketing in Health Care. Journal of Health Care Marketing, Vol. 14, No. 4, Winter, 42-46.

Wagner, J., and Falkson, J. (1975). The Optimal Nodal Location of Public Facilities with Price-Sensitive Demand. Geographical Analysis, Vol. 7. 69:83.

Williams, S. J. and Guerra, Sandra (1985). A Consumer's Guide to Health Care Services. Englewood Cliffs, Prentice-Hall, Inc.

Winston, William, J. (1985). Marketing Ambulatory Care Services. New York: The Haworth Press, Inc. New York.

Wolfson, J., G. Walker and Levin, P. J. (1993). Freestanding Ambulatory Surgery: Cost-Containment Winner? Health Care Financial Management, July, 27-32.

Woodside, A. G., et al., (1988). Preference Segmentation of Health Care Services: The Old-fashioned, Value-conscious, Affluent and Professional Want-it-alls. Journal of Health Care Marketing, Vol. 8, No. 2, June, 14-24. 
Wotruba, T. R., Hass, R. W., and Oulhen, H. (1985). Marketing Factors Affecting Physician Choice as Related to Consumers' Extent of Use and Predisposition Toward Use of Physician Services. Journal of Health Care Marketing, Vol. 5, No. 4, Fall, 7-17.

Zajas, J. (1994). Obstacles to Real Strategic Marketing in Health Care: An

Experimental Framework. Journal of Hospital Marketing, Vol. 8(2): 19-30.

Zwanziger, J., Melnick, G. and Eyre, K. (1994). Hospitals and Antitrust: Defining Markets, Setting Standards. Journal of Health Politics, Policy and Law, Vol. 19, No. 2, Summer. Duke University Press. 
APPENDIX A

SURVEY QUESTIONNAIRE AND LIST OF CLINICS 


\section{The Survey Questionnaire}

I am a $\mathrm{Ph}$. D. student at Portland State University. I am doing a survey of all the providers of urgent care in 1990 for the Portland metropolitan area, and would like to get some information about your clinic as of the year 1990. Do you know who can provide me with this information?

May you please answer the following questions as the conditions were in 1990 , to the best of your knowledge?

Q. 1. What was the type of service you used to provide in 1990 ? Was it :

General Medicine, or

Specialty?

Q. 2. What were your daily operating hours?

Week days

Week ends

Q. 3. Did you accept walk-in patients?

Q. 4. How did you classify your appointment flexibility in 1990 ? 
Immediate

Convenient, such as same day appointment, or advanced appointment necessary?

Q.5. Did your clinic have emergency facilities?

Ambulatory unit,

X Ray?

Q. 6. What was your address and major intersection?

Same location, or

new location?

Q. 7. What of the following was close by, in the range of two miles, from your clinic, in 1990:

A major hospital, (specify if your hospital or competitor)?

Some medical practitioner offices?

Medical research or lab facilities?

Q. 8. Was there any other urgent care center close by your clinic in 1990 ?

Q. 9. What was the name of the health care organization your clinic belonged to? 
The survey covered all medical clinics in the Portland tri-county metropolitan area. Table (2a) presents the detailed information gathered by the survey. Based on the operational definition of this study, a selection was made to include only those clinics that met the definition criteria, which are discussed in Chapter IV. Table (2b) presents a summary of the UCCs that met the definition of this study. A list of the UCCs that met this study's operational definition is presented in Chapter IV.

TABLE (2a) Providers of Urgent Care in Portland, Oregon, 1990

Detailed answers from respondents to the survey questions, as of $\mathbf{1 9 9 0 .}$

\begin{tabular}{|c|c|c|c|c|c|c|c|c|}
\hline \multirow[t]{2}{*}{ Provider } & \multirow[t]{2}{*}{ Location } & \multicolumn{5}{|c|}{$\left[\begin{array}{l}\text { Type of } \\
\text { Service }\end{array}\right.$} & \multicolumn{2}{|c|}{ Operation Hrs. } \\
\hline & & \multicolumn{5}{|c|}{ 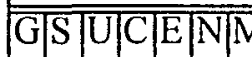 } & W.D & W.E \\
\hline Sisters of & St. Vincent & * & * & $T^{*}$ & & * & $10-10$ & $10-10$ \\
\hline Providence & Milwaukie & * & * & * & & * & $10-10$ & $10-10$ \\
\hline & Portland M.C. & * & * & * & & * & $10-10$ & $10-10$ \\
\hline & Mercantile & * & * & * & & * & $10-8$ & $10-8$ \\
\hline & Scholls & * & * & * & & * & $10-8$ & $10-8$ \\
\hline & Tanasbourne & * & * & $x$ & & * & $10-8$ & $10-8$ \\
\hline & Sunnyside & * & * & : & & * & $10-8$ & $10-8$ \\
\hline & Wilsonville & * & * & - & & * & $10-8$ & $10-8$ \\
\hline & Vermont & * & * & $=$ & & * & $10-8$ & $10-8$ \\
\hline & Parkrose Plza & $*$ & * & $=$ & & * & $10-8$ & $10-8$ \\
\hline
\end{tabular}




\begin{tabular}{|c|c|c|c|c|c|c|c|c|}
\hline Legacy & $\begin{array}{l}\text { Emanuel } \\
\text { Good Sam. } \\
\text { Meridian } \\
\text { Park } \\
\text { Gresham } \\
\text { Milwaukie } \\
\text { Tigard }\end{array}$ & $\begin{array}{l}* \\
* \\
* \\
* \\
*\end{array}$ & $\begin{array}{l}* \\
* \\
* \\
* \\
* \\
* \\
*\end{array}$ & $\begin{array}{l}* \\
* \\
* \\
* \\
* \\
*\end{array}$ & & $\begin{array}{l}* \\
* \\
* \\
* \\
*\end{array}$ & $\begin{array}{l}8-8 \\
9-9 \\
9-9 \\
9-9 \\
9-9 \\
9-9 \\
9-9\end{array}$ & $\begin{array}{c}10-8 \\
9-9 \\
9-9 \\
9-9 \\
9-9 \\
9-9 \\
9-9\end{array}$ \\
\hline $\begin{array}{l}\text { Oregon } \\
\text { Health } \\
\text { Sciences } \\
\text { University }\end{array}$ & Portland & * & & & * & * & $9-5$ & $\cdots$ \\
\hline $\begin{array}{l}\text { Kaiser } \\
\text { Permanente }\end{array}$ & $\begin{array}{l}\text { Greeley } \\
\text { Sunnyside } \\
\text { Beaverton }\end{array}$ & $\begin{array}{l} \\
* \\
*\end{array}$ & & $\begin{array}{lll}* & * \\
* & *\end{array}$ & & * & $\begin{array}{l}24 \mathrm{~h} \\
8-8 \\
8-8\end{array}$ & $\begin{array}{c}24 \mathrm{~h} \\
8-8 \\
8-8\end{array}$ \\
\hline $\begin{array}{l}\text { The Portland } \\
\text { Clinic }\end{array}$ & $\begin{array}{l}\text { Tigard } \\
\text { Portland } \\
\text { Beaverton }\end{array}$ & $\begin{array}{l}* \\
* \\
*\end{array}$ & & \begin{tabular}{l|l}
$*$ & $*$ \\
$*$ & $*$ \\
$*$
\end{tabular} & & * & $\begin{array}{l}6-8 \\
6-8 \\
6-8\end{array}$ & $\begin{array}{l}\text { varies } \\
\text { varies } \\
\text { varies }\end{array}$ \\
\hline $\begin{array}{l}\text { The Family } \\
\text { Medical } \\
\text { Center }\end{array}$ & Tigard & * & $\bar{*}$ & * & & * & $8-8$ & $9-4$ \\
\hline $\begin{array}{l}\text { Metropolitan } \\
\text { Clinic PC }\end{array}$ & $\begin{array}{l}\text { N.Broadway } \\
\text { Tigard } \\
\text { N.W. 22nd }\end{array}$ & $\begin{array}{l}* \\
* \\
*\end{array}$ & * & * & * & * & $\begin{array}{l}9-6 \\
8-9 \\
9-6\end{array}$ & $\begin{array}{l}\cdots-- \\
10-4 \\
---\end{array}$ \\
\hline Tuality & $\begin{array}{l}\text { Aloha } \\
\text { Tanasbourne } \\
\text { Forest Grove }\end{array}$ & $\begin{array}{l}* \\
* \\
*\end{array}$ & * & & & * & $\begin{array}{l}8-9 \\
8-9 \\
8-9\end{array}$ & $\begin{array}{l}8-9 \\
8-9 \\
8-9\end{array}$ \\
\hline $\begin{array}{l}\text { Portland } \\
\text { Adventist } \\
\text { M.C }\end{array}$ & $\begin{array}{l}\text { Portland } \\
\text { Clackamas }\end{array}$ & $\begin{array}{l}* \\
*\end{array}$ & & * & & * & $\begin{array}{l}7-10 \\
7-10\end{array}$ & $\begin{array}{l}10-6 \\
10-6\end{array}$ \\
\hline $\begin{array}{l}\text { Willamette } \\
\text { Falls } \\
\text { Hospital }\end{array}$ & $\begin{array}{l}\text { Clackamas } \\
\text { Oregon City }\end{array}$ & * & $*$ & $* *$ & & * & $\begin{array}{l}9-9 \\
9-9\end{array}$ & $\begin{array}{l}10-6 \\
10-4\end{array}$ \\
\hline $\begin{array}{l}\text { Woodland } \\
\text { Park Hospital }\end{array}$ & Portland & * & * & * & & $*$ & 24 h. & $24 \mathrm{~h}$. \\
\hline \begin{tabular}{l|} 
Suburban \\
Clinics
\end{tabular} & Gresham & $*$ & * & * & & ॠ & $6-9$ & $10-7$ \\
\hline $\begin{array}{l}\text { Lake Oswego } \\
\text { Clinic }\end{array}$ & Lake Oswego & * & & k & & * & $8-9$ & $10-5$ \\
\hline \begin{tabular}{|l|} 
North \\
Portland C.
\end{tabular} & Portland & * & & * & & & $8-7$ & $10-4$ \\
\hline $\begin{array}{l}\text { Eastmoreland } \\
\text { Hospital }\end{array}$ & Portland & * & * & F & & * & & \\
\hline
\end{tabular}




\begin{tabular}{|c|c|c|c|c|c|c|c|c|}
\hline $\begin{array}{l}\text { Beaverton } \\
\text { Primary Care }\end{array}$ & Beaverton & T & & $T^{*}$ & & & $8-8$ & $\overline{8-8}$ \\
\hline $\begin{array}{l}\text { Cedar Hills } \\
\text { Fam. Clinic }\end{array}$ & Beaverton & * & & & \# & & $9-5$ & -- \\
\hline $\begin{array}{l}\text { East Portland } \\
\text { Family Clinic }\end{array}$ & S.E. Division & * & & & * & & $9-6$ & -- \\
\hline $\begin{array}{l}\text { Oak } \\
\text { G.Fam.MG }\end{array}$ & $\begin{array}{l}\text { Oak Grove, } \\
\text { Milw. }\end{array}$ & * & & & * & & $9-5$ & $\cdots$ \\
\hline Omni M.G & Wilsonvl. & * & & & F & & $9-5$ & \\
\hline $\begin{array}{l}\text { The Primary } \\
\text { Care Clinic }\end{array}$ & N.W 22nd & * & & & * & & $9-5$ & \\
\hline $\begin{array}{l}\text { St. Johns } \\
\text { Clinic }\end{array}$ & N. Lombard & * & & & * & & $9-6$ & \\
\hline $\begin{array}{l}\text { Winans } \\
\text { Medical } \\
\text { Center }\end{array}$ & Tigard & * & & & * & & $9-6$ & \\
\hline \begin{tabular}{|l} 
Doctor's \\
Family Clinic
\end{tabular} & Beaverton & * & 政 & $\%$ & & F & $8-9$ & $9-6$ \\
\hline $\begin{array}{l}\text { Mt. Tabor } \\
\text { Clinic }\end{array}$ & S.E. Belmont & * & & $* *$ & & * & $8-8$ & varies \\
\hline Total & 49 & & & & & & & \\
\hline
\end{tabular}

G : General health care.

S : $\quad$ Specialty only, such as pediatrics or obstetrics.

$\mathrm{U}$ : $\quad$ Urgent care, no appointment needed.

C : $\quad$ Convenient care, same day appointment.

E : $\quad$ Extended hours of operation, before $9 \mathrm{AM}$ and after $5 \mathrm{pm}$.

$\mathrm{N}$ : $\quad$ Normal business hours from 9 to 5 only.

M: $\quad$ Emergency facilities to provide urgent care. 
CONT. TABLE (2a) Providers of Urgent Care in Portland, Oregon, 1990

Detailed answers from respondents to the survey questions, as of 1990 .

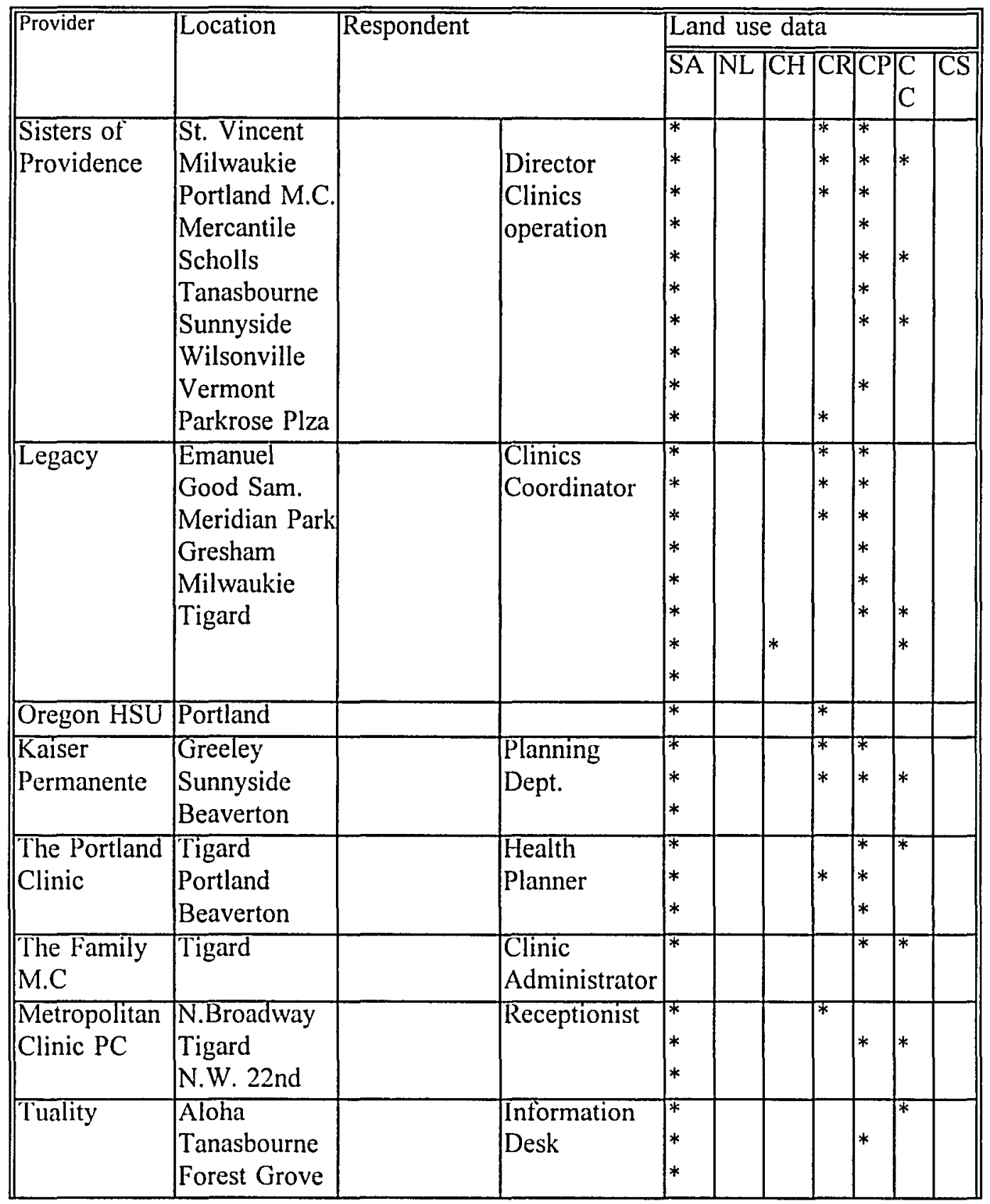




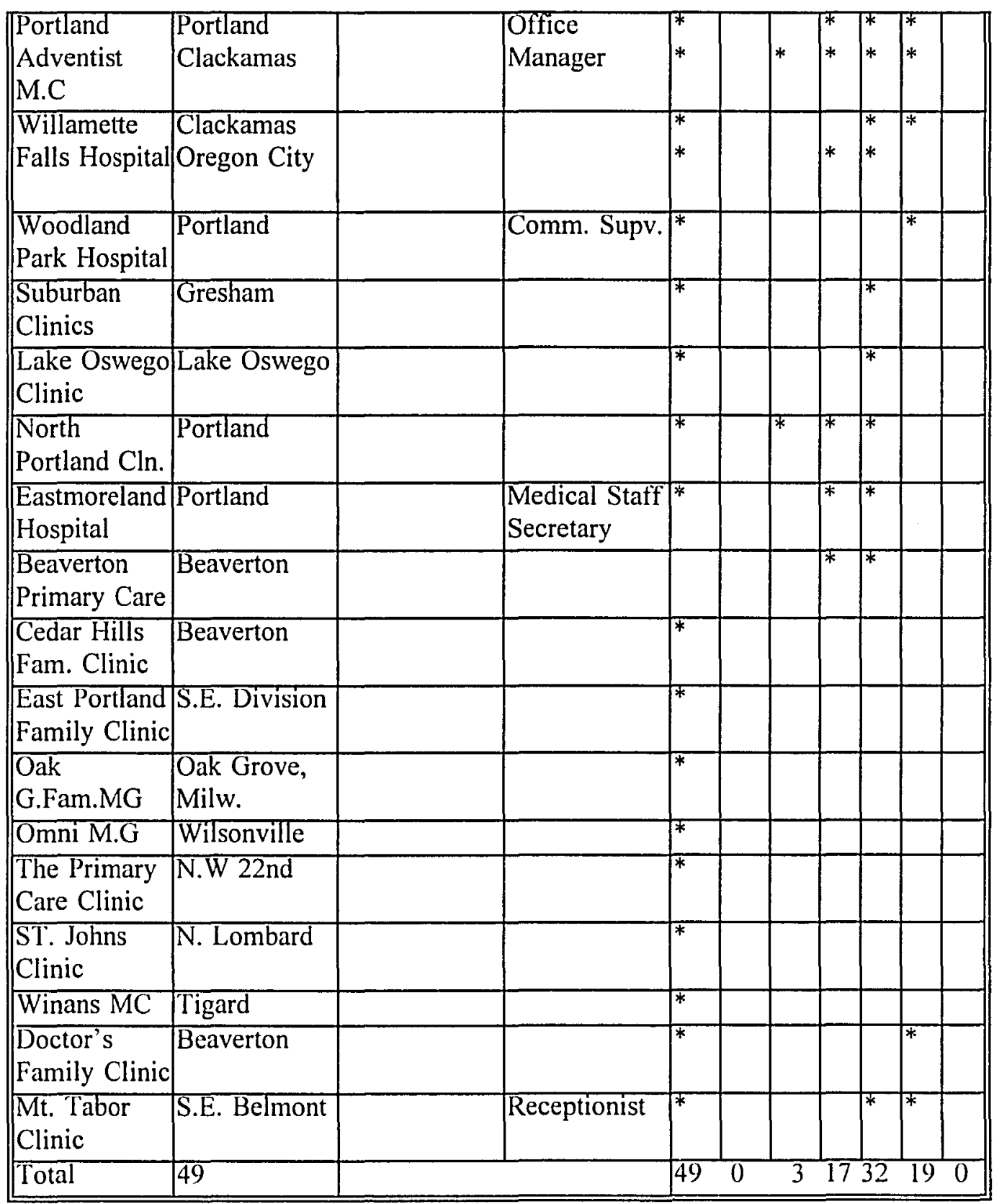

G : $\quad$ General health care.

S : $\quad$ Specialty only, such as pediatrics or obstetrics.

$\mathrm{U}$ : $\quad$ Urgent care, no appointment needed.

C : $\quad$ Convenient care, same day appointment.

E : $\quad$ Extended hours of operation, before $9 \mathrm{AM}$ and after $5 \mathrm{pm}$.

$\mathrm{N}$ : $\quad$ Normal business hours from 9 to 5 only. 
M: $\quad$ Emergency facilities to provide urgent care.

SL: $\quad$ Same location

NL: New location

$\mathrm{CH}$ : $\quad$ Close by hospitals

CP: Close by practitioners offices

CR: Close by research or medical labs

CC: Close by competitors

CS: Close by Sister UCCs.

*: $\quad$ Yes

1: Telephone number is disconnected, However they have a advertisement in the 1990 U.S. West Yellow Pages.

Source: Based on 1990-1991 U. S. West Telephone Directory and phone calls. 
TABLE (2b) Providers of Urgent Care in Portland, Oregon, 1990

\begin{tabular}{|c|c|c|c|c|c|c|c|c|c|}
\hline \multirow[t]{2}{*}{ Provider } & \multirow[t]{2}{*}{ Location } & \multicolumn{7}{|c|}{ Type of Service } & \multirow{2}{*}{$\begin{array}{l}\text { Number of } \\
\text { Clinics }\end{array}$} \\
\hline & & $\mathrm{G}$ & $S$ & $\mathrm{U}$ & $\mathrm{C}$ & $\mathrm{E}$ & $\mathrm{N}$ & $\mathrm{M}$ & \\
\hline $\begin{array}{l}\text { Sisters of } \\
\text { Providence }\end{array}$ & $\begin{array}{l}\text { St. Vincent } \\
\text { Milwaukie } \\
\text { Providence M.C. } \\
\text { Mercantile } \\
\text { Scholls } \\
\text { Tanasbourne } \\
\text { Sunnyside } \\
\text { Wilsonville } \\
\text { Vermont } \\
\text { Parkrose Plaza }\end{array}$ & $\begin{array}{l}* \\
* \\
* \\
* \\
* \\
* \\
* \\
* \\
*\end{array}$ & & $\begin{array}{l}* \\
* \\
* \\
* \\
* \\
* \\
* \\
* \\
*\end{array}$ & & $\begin{array}{l}* \\
* \\
* \\
* \\
* \\
* \\
* \\
* \\
* \\
*\end{array}$ & & $\begin{array}{l}* \\
* \\
* \\
* \\
* \\
* \\
* \\
* \\
* \\
*\end{array}$ & 10 \\
\hline Legacy & $\begin{array}{l}\text { Emanuel } \\
\text { Good Samaritan } \\
\text { Meridian Park } \\
\text { Gresham } \\
\text { Milwaukie } \\
\text { Tigard }\end{array}$ & $\begin{array}{l}* \\
* \\
* \\
* \\
*\end{array}$ & & $\begin{array}{l}* \\
* \\
* \\
* \\
*\end{array}$ & & $\begin{array}{l}* \\
* \\
* \\
* \\
* \\
*\end{array}$ & & $\begin{array}{l}* \\
* \\
* \\
* \\
* \\
*\end{array}$ & 6 \\
\hline $\begin{array}{l}\text { Oregon Health } \\
\text { Sciences } \\
\text { University }\end{array}$ & Portand & $*$ & & & & & $n$ & $*$ & 1 \\
\hline $\begin{array}{l}\text { Kaiser } \\
\text { Permanente }\end{array}$ & $\begin{array}{l}\text { Greeley } \\
\text { Sunnyside } \\
\text { Beaverton }\end{array}$ & $\begin{array}{l}* \\
* \\
*\end{array}$ & & & * & * & & " & 3 \\
\hline $\begin{array}{l}\text { The Portland } \\
\text { Clinic }\end{array}$ & $\begin{array}{l}\text { Tigard } \\
\text { Portland } \\
\text { Beaverton }\end{array}$ & $\begin{array}{l}* \\
* \\
*\end{array}$ & & & * & * & & $\begin{array}{l}* \\
* \\
*\end{array}$ & 3 \\
\hline
\end{tabular}




\begin{tabular}{|c|c|c|c|c|c|c|c|c|}
\hline $\begin{array}{l}\text { The Family } \\
\text { Medical Center }\end{array}$ & Tigard & $*$ & $*$ & & * & & * & 1 \\
\hline $\begin{array}{l}\text { Metropolitan } \\
\text { Clinic PC }\end{array}$ & $\begin{array}{l}\text { N.Broadway } \\
\text { Tigard } \\
1130 \text { N.W. 22nd }\end{array}$ & * & * & & * & * & * & 3 \\
\hline Tuality & $\begin{array}{l}\text { Aloha } \\
\text { Tanasbourne } \\
\text { Forest Grove }\end{array}$ & * & * & & & & * & 3 \\
\hline $\begin{array}{l}\text { Portland } \\
\text { Adventist Medical } \\
\text { Center }\end{array}$ & $\begin{array}{l}\text { Portland } \\
\text { Clackamas }\end{array}$ & * & & * & * & & * & 2 \\
\hline $\begin{array}{l}\text { Willamette Falls } \\
\text { Hospital }\end{array}$ & $\begin{array}{l}\text { Clackamas } \\
\text { Oregon City }\end{array}$ & * & * & $*$ & * & & * & 2 \\
\hline $\begin{array}{l}\text { Woodland Park } \\
\text { Hospital }\end{array}$ & Portland & * & * & & $*$ & & * & 1 \\
\hline Suburban Clinics & Gresham & $*$ & * & & * & & $*$ & 1 \\
\hline $\begin{array}{l}\text { Lake Oswego } \\
\text { Clinic }\end{array}$ & Lake Oswego & * & & $*$ & * & & * & 1 \\
\hline $\begin{array}{l}\text { North Portland } \\
\text { Clinic }\end{array}$ & Portland & $*$ & & $*$ & * & & * & 1 \\
\hline $\begin{array}{l}\text { Eastmoreland } \\
\text { Hospital }\end{array}$ & Portand & * & * & & $*$ & & * & 1 \\
\hline $\begin{array}{l}\text { Beaverton } \\
\text { Primary Care }\end{array}$ & Beaverton & * & & * & & $*$ & & 1 \\
\hline $\begin{array}{l}\text { Cedar Hills Fam. } \\
\text { Clinic }\end{array}$ & Beaverton & * & & & & * & & 1 \\
\hline $\begin{array}{l}\text { East Portland } \\
\text { Family Clinic }\end{array}$ & S.E. Division & $*$ & & & & * & & 1 \\
\hline $\begin{array}{l}\text { Oak Grove } \\
\text { Family Medical } \\
\text { Group }\end{array}$ & $\begin{array}{l}\text { S.E. Oat Grove. } \\
\text { Milw. }\end{array}$ & $*$ & & & & * & & 1 \\
\hline $\begin{array}{l}\text { Omni Nledical } \\
\text { Group }\end{array}$ & Wilsom ille. & $*$ & & & & $*$ & & 1 \\
\hline
\end{tabular}




\begin{tabular}{|l|l|l|l|l|l|l|l|l|l||}
\hline $\begin{array}{l}\text { The Primary Care } \\
\text { Clinic }\end{array}$ & N.W 22nd & $*$ & & & & & $*$ & & 1 \\
\hline ST. Johns Clinic & N. Lombard & $*$ & & & & & $*$ & & 1 \\
\hline $\begin{array}{l}\text { Winans Medical } \\
\text { Center }\end{array}$ & Tigard & $*$ & & & & & $*$ & & 1 \\
\hline $\begin{array}{l}\text { Doctor's Family } \\
\text { Clinic }\end{array}$ & Beaverton & $*$ & & $*$ & & $*$ & & $*$ & 1 \\
\hline Mt. Tabor Clinic & S.E. Belmont & $*$ & & & $*$ & $*$ & & $*$ & 1 \\
\hline Total & & & & & & 51 \\
\hline
\end{tabular}

G : General health care.

S : Specialty only, such as pediatrics or obstetrics.

$\mathrm{U}$ : Urgent care, no appointment needed.

C : Convenient care, same day appointment.

$\mathrm{E}$ : Extended hours of operation, before $9 \mathrm{AM}$ and after $5 \mathrm{pm}$.

$N$ : Normal business hours from 9 to 5 only.

$\mathrm{M}$ : Emergency Facilities.

Source: Based on 1990-1991 U. S. West Telephone Directory and phone calls. 
APPENDIX B

THE DESCRIPTIVE STATISTICS RESULTS 
Summaries of WHITES

\begin{tabular}{lll} 
& Mean & Std Dev \\
\cline { 2 - 3 } For Entire Population & 3900.1612 & 1886.2617 \\
0 ucc not present & 3897.4958 & 1875.1364 \\
1 ucc present & 3919.5455 & 1995.3126
\end{tabular}

Summaries of CHILDREN

\begin{tabular}{lll} 
& Mean & Std Dev \\
\cline { 2 - 3 } For Entire Population & 1124.9011 & 633.9030 \\
0 ucc not present & 1140.3875 & 640.1800 \\
1 ucc present & 1012.2727 & 582.9058
\end{tabular}

Summaries of ELDERLY

\begin{tabular}{lcc} 
& Mean & Std Dev \\
\cline { 2 - 3 } For Entire Population & 522.5458 & 301.2490 \\
\hline ucc not present & 511.0750 & 286.2085 \\
1 ucc present & 605.9697 & 389.1195
\end{tabular}




\section{Summaries of INCM}

\begin{tabular}{lcc} 
& Mean & Std Dev \\
\cline { 2 - 3 } For Entire Population & 736.9048 & 459.6963 \\
0 ucc not present & 733.0250 & 454.4011 \\
1 ucc present & 765.1212 & 503.1320
\end{tabular}

\section{Summaries of PFEMALES}

\begin{tabular}{lll} 
& Mean & Std Dev \\
\cline { 2 - 3 } For Entire Population & .5071 & .0465 \\
0 ucc not present & .5056 & .0484 \\
1 ucc present & .5182 & .0255
\end{tabular}


APPENDIX C

THE LOGIT ANALYSIS RESULTS 


\section{The Logit Analysis Model Outputs}

This appendix presents the resulted outputs of both: (1) the primary logit model with all the demographic and socioeconomic variable, and (2) the same model with the adjacency of the population size for each $\mathrm{C}$ as a proxy to all demographic and socioeconomic variables.

\section{The primary model:}

Total number of cases: 273 (Unweighted)

Number of selected cases: 273

Number of unselected cases: 0

Number of selected cases:

Number rejected because of missing data: 0

Number of cases included in the analysis: 273

$\begin{array}{ll}-2 \text { Log Likelihood } & 111.257 \\ \text { Goodness of Fit } & 276.602\end{array}$

Chi-Square df Significance

$\begin{array}{llll}\text { Model Chi-Square } & 86.036 & 11 & .0000\end{array}$

$\begin{array}{llll}\text { Improvement } & 86.036 & 11 & .0000\end{array}$

TABLE (1C) Classification Table for UCC Predicted

\begin{tabular}{||l||l|l|l||}
\hline Predictions & $\begin{array}{l}\text { UCC Not } \\
\text { Present }\end{array}$ & $\begin{array}{l}\text { UCC } \\
\text { Present }\end{array}$ & $\begin{array}{l}\text { Percent } \\
\text { Correct }\end{array}$ \\
\hline \hline UCC Not Pesent & 239 & 2 & $99.17 \%$ \\
\hline UCC Present & 19 & 13 & $40.63 \%$ \\
\hline
\end{tabular}


TABLE (2C) Detailed Logit Analysis Results

\begin{tabular}{|c|c|c|c|c|c|c|c|}
\hline Variable & $\mathbf{B}$ & S.E. & Wald & df & Sig & $\mathbf{R}$ & $\operatorname{Exp}(B)$ \\
\hline $\begin{array}{l}\text { ACHILD } \\
\text { AELDER } \\
\text { AFEMALE } \\
\text { AINCOME } \\
\text { AWHITE } \\
\text { COMP } \\
\text { ECON } \\
\text { GROWTH } \\
\text { HOSPITAI } \\
\text { OFFICE } \\
\text { VT } \\
\text { COngtant }\end{array}$ & $\begin{array}{r}.0002 \\
.0006 \\
-.0007 \\
.0001 \\
.0002 \\
12.7679 \\
2.1709 \\
.0005 \\
.3472 \\
6.99 \mathrm{E}-06 \\
1.0614 \\
-5.0110\end{array}$ & $\begin{array}{r}.0004 \\
.0005 \\
.0005 \\
.0003 \\
.0002 \\
24.0063 \\
.7996 \\
.0016 \\
.5361 \\
5.385 \mathrm{E}-05 \\
.5396 \\
1.0900\end{array}$ & $\begin{array}{r}.3251 \\
1.2750 \\
2.1281 \\
.2238 \\
1.3369 \\
.2829 \\
7.3709 \\
.1182 \\
.4194 \\
.0169 \\
3.8694 \\
21.1337\end{array}$ & $\begin{array}{l}1 \\
1 \\
1 \\
1 \\
1 \\
1 \\
1 \\
1 \\
1 \\
1 \\
1 \\
1\end{array}$ & $\begin{array}{l}.5686 \\
.2588 \\
.1446 \\
.6362 \\
.2476 \\
.5948 \\
.0066 \\
.7310 \\
.5172 \\
.8967 \\
.0492 \\
.0000\end{array}$ & $\begin{array}{r}.0000 \\
.0000 \\
.0255 \\
.0000 \\
.0000 \\
.0000 \\
.1650 \\
.0000 \\
.0000 \\
.0000 \\
.0973\end{array}$ & $\begin{array}{r}1.0002 \\
1.0006 \\
.9993 \\
1.0001 \\
1.0002 \\
350757.8 \\
8.7660 \\
1.0005 \\
1.4151 \\
1.0000 \\
2.8904\end{array}$ \\
\hline
\end{tabular}

\section{The population size model}

Total number of cases: 273 (Unweighted)

Number of selected cases: 273

Number of unselected cases: 0

Number of selected cases: $\quad 273$

Number rejected because of missing data: 0

Number of cases included in the analysis: 273

-2 Log Likelihood 197.29238

-2 Log Likelihood

Model Chi-Square

Improvement

Goodness of Fit
Chi-Square df Significance

$\begin{array}{rrr}114.728 & 265 & 1.000 \\ 82.564 & 7 & .0000 \\ 82.564 & 7 & .0000 \\ 250.270 & 265 & .7334\end{array}$


TABLE (3C) Classification Table for UCC Predicted

\begin{tabular}{||l||l|l|l||}
\hline Predictions & $\begin{array}{l}\text { UCC Not } \\
\text { Present }\end{array}$ & $\begin{array}{l}\text { UCC } \\
\text { Present }\end{array}$ & $\begin{array}{l}\text { Percent } \\
\text { Correct }\end{array}$ \\
\hline \hline UCC Not Pesent & 241 & 0 & $100 \%$ \\
\hline UCC Present & 19 & 13 & $40.63 \%$ \\
\hline
\end{tabular}

TABLE (4c) Detailed Logit analysis Results

\begin{tabular}{lrrrrrrr}
\hline Variable & \multicolumn{1}{c}{ B } & S.E. & Wald & df & Sig & R & Exp(B) \\
\hline HOSPITAL & .4724 & .5141 & .8444 & 1 & .3581 & .0000 & 1.6039 \\
OFFICE & $1.19 E-05$ & $5.284 E-05$ & .0511 & 1 & .8211 & .0000 & 1.0000 \\
GROWTH & .0015 & .0014 & 1.1586 & 1 & .2818 & .0000 & 1.0015 \\
ECON & 2.1248 & .7730 & 7.5551 & 1 & .0060 & .1678 & 8.3709 \\
VT & .8465 & .5135 & 2.7178 & 1 & .0992 & .0603 & 2.3315 \\
COMP & 11.8453 & 25.0628 & .2234 & 1 & .6365 & .0000 & 139426.4 \\
APOP & $1.32 \mathrm{E}-05$ & $2.294 \mathrm{E}-05$ & .3300 & 1 & .5657 & .0000 & 1.0000 \\
ConBtant & -5.2005 & 1.0348 & 25.2549 & 1 & .0000 & & \\
\hline
\end{tabular}

